\title{
A Method for Evaluating the Formability of Tailor Rolled Blank (TRB) by Means of the Forming Limit Margin Field Graph in Forming Process
}

\section{Da Cai}

Hunan University

Hang Ou

Hunan University

Ming Hu

Hunan University

Guangyao Li

Hunan University

Junjia Cui ( $\square$ cuijunjia@hnu.edu.cn )

Hunan University https://orcid.org/0000-0001-8004-6030

\section{Research Article}

Keywords: Tailor rolled blank (TRB), Forming limit margin filed graph, Quantitative evaluation of formability, Cracking prediction

Posted Date: April 28th, 2021

DOl: https://doi.org/10.21203/rs.3.rs-447084/v1

License: (c) (i) This work is licensed under a Creative Commons Attribution 4.0 International License. Read Full License 


\title{
A method for evaluating the formability of tailor rolled blank (TRB) by means of the forming limit margin field graph in forming process
}

\author{
Da Cai, Hang Ou, Ming Hu, Guangyao Li, Junjia Cui * \\ State Key Laboratory of Advanced Design and Manufacturing for Vehicle Body, \\ Hunan University, Changsha, 410082, China
}

\begin{abstract}
Tailor rolled blank (TRB) with graded thickness has shown great potential in the automobile field. Using traditional forming limit diagrams (FLDs) to evaluate TRB formability is challenging due to thickness variations. In this paper, a 3D forming limit surface (FLS) considering the influence of thickness was obtained. A numerical model was developed to predict final strains. Moreover, a forming margin was denoted and calculated to generate the forming limit margin field graph for quantitative evaluation of the TRB formability. Results showed that as the punch travel increased, the forming margin value decreased. As the travel changed from $35.2 \mathrm{~mm}$ to $37.4 \mathrm{~mm}$, the corresponding forming margin value changed from 0.002 to -0.024 . The formability declined, and the specimen eventually cracked on the thinner side. Besides, the deformation and strain paths predicted by simulation agreed well with those measured from formed part, which indicated that the final strains used in formability evaluation were reliable. The method was suitable for quantitative evaluation of the formability and predicting the cracking position in TRB forming.
\end{abstract}

Keywords: Tailor rolled blank (TRB); Forming limit margin filed graph; Quantitative evaluation of formability; Cracking prediction

\footnotetext{
* Corresponding author: Tel.: +86 731 88664001; Fax:+86 731 88822051; Email: cuijunjia@hnu.edu.cn
} 


\section{Introduction}

With the increasing demand for high-performance materials in the automobile and aerospace industries, the application of lightweight materials such as aluminum alloys and high-strength steels has become more and more extensive. Advanced manufacturing technologies open up new possibilities for the application of lightweight materials [1-3]. Tailor rolled blank (TRB) with graded thickness obtained by rolling was regard as a potential lightweight metal sheet [4]. As shown in Fig. 1, the TRB rolling process was continuous. The constant thickness zone and thickness transition zone were made by adjusting the roll gap online according to actual needs. There was no abrupt change in thickness along the rolling direction, so that TRB could have good surface quality and excellent formability [5-7]. Due to the remarkable advantages of TRB, some well-known automotive manufacturers have introduced TRB in their products to reduce the vehicle weight [8-10].

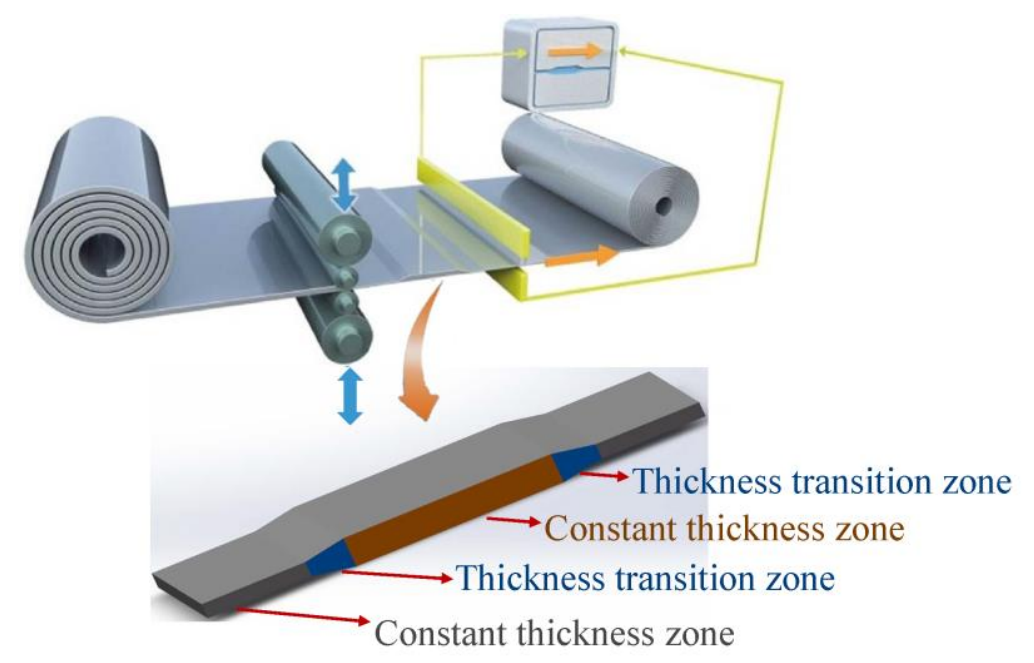

Fig. 1 A schematic of TRB technology (adapted from Ref. [4])

The prediction of material formability has been a key requirement in the forming process of TRB applications. The formability prediction aimed to increase productivity by reducing the number of failures. To predict the cracking of TRB in forming process, criteria for the evaluation of TRB formability should be established. One way to evaluate the formability of a formed part was by thinning. In industrial applications, the formed part with a thinning rate of more than $15 \%$ was generally considered scrap. However, the evaluation only through thinning was not sufficient, it was also inaccurate 
without considering the sheet material parameters. The forming limit diagram (FLD) worked as another effective limiting criterion to describe the deformation degree of materials without cracking $[11,12]$. It represented the largest major and minor strains that a blank could withstand before necking or cracking occurred in all possible combinations of strain paths during forming. Theoretically, the FLD used in TRB forming should contain an infinite number of forming limit curves (FLCs).

To obtain the FLCs, empirical methods and experiments could be used. Ghazanfari et al. [13] proposed an empirical law in terms of sheet thickness to determine FLD without experimental data. Abspoel et al. [14] derived predictive equations of the FLCs from the statistical relations between the measured FLC points and the mechanical properties. Kim et al. [15] used various constitutive models to predict the formability of high strength steels. Although the cost of experiments was higher than that of empirical methods, the experimental results were more realistic and direct. The Nakazima test was a standard experiment that provided the sheet formability information. Holmberg et al. [16] developed a test method which can quickly determine the forming limit in plane. The tests were carried out in a tensile testing machine.

Previous studies on the formability of TRB were mainly focused on the forming limit in deep drawing process. Mayer et al. [8] used TRB to increase the maximum deep drawing depth. They evaluated the results through two-dimensional FLD of the sheet with constant thickness. Zhang et al. [9] discussed forming limit of TRB square box during the drawing process. The formability evaluation criteria they used were maximum drawing depth and thinning. These studies did not take into account the continuous thickness variation in the thickness transition zone. Moreover, there was little quantitative evaluation of formability in these studies. The thickness of TRB was continuously changing. The mechanical properties and formability of different thickness were different [17]. Quantitative assessment of the safety degree and the cracking degree can contribute to the design and production of TRB applications. Therefore, it is necessary to establish a criterion by considering the thickness effect in the TRB forming process. The criterion should have the ability to evaluate the formability quantitatively. 
In this paper, the forming limit margin field graph was proposed to quantify the formability and predict cracking. The method could be divided into four steps. Firstly, a 3D forming limit surface (FLS) was established based on the FLCs in the constant thicknesses zone. Secondly, uniaxial tensile tests and the Lagrange interpolation method were used to obtain the constitutive relation of the TRB. Thirdly, a numerical model was established to obtain major and minor strains of all elements. Finally, forming margins were calculated based on major strains, minor strains and the FLS. The forming limit margin field graph was established and verified by the experiment.

\section{Forming limit margin field graph}

\section{1. $3 D$ forming limit surface}

The FLD obtained by experiments or empirical methods has proven to be a good failure criterion. In order to better analyze the deformation process of TRB, the traditional 2D FLCs were replaced by the 3D FLS. The process of obtaining the FLS was divided into two steps. Firstly, the FLCs in the constant thicknesses zone were obtained by the forming limit test. Secondly, upon the basis of the FLCs, the FLS was constructed by polynomial fitting.

The FLCs of HC340LA under thicknesses of $1.2 \mathrm{~mm}, 1.4 \mathrm{~mm}, 1.6 \mathrm{~mm}$ and 1.8 $\mathrm{mm}$ were selected [17]. Nine types of geometrics in each group were applied to obtain different strain paths and the FLC. The forming limit tests combined with the 3D Digital Image Correlation (DIC) technology were carried out. The limit strains were determined by the combination of position dependent method and DIC technology. The FLCs were obtained by fitting.

To obtain the forming limit in the thickness transition zone, the polynomial interpolation method was adopted. The 3D FLS of TRB was obtained by fitting the four FLCs. In the method, the minor strain was defined as $x$, the thickness was defined as $y$ and the major strain was defined as $z$. The relationship between the fitting result and the actual value can be defined by the following equation:

$$
z(x, y)=z_{\text {fitting }}(x, y)+\varepsilon
$$

where $z_{\text {fitting }}(x, y)$ represents fitted polynomial, and $\varepsilon$ represents synthetic error. For 
polynomial fitting surface, the goodness of fit was used to evaluate the surface fitting accuracy. The coefficient of determination (R-square) and the root mean squared error relative error (RMSE) were important statistics to measure goodness of fit.

R-square can be defined as

$$
R-\text { square }=1-\frac{\sum_{i=1}^{n} \varepsilon_{i}^{2}}{\sum_{i=1}^{n}\left(z_{i}-\bar{z}_{i}\right)^{2}}\left(i=1,2, \ldots, n_{e}\right)
$$

RMSE can be defined as

$$
R M S E=\sqrt{\frac{1}{n} \sum_{i=1}^{n} \varepsilon_{i}^{2}}\left(i=1,2, \ldots, n_{e}\right)
$$

where $\varepsilon_{i}$ is the synthetic error value at the test point, $\bar{z}_{i}$ is the mean of the measured major strain data. The polynomial used to fit the 3D FLS can be defined by Eq. (4):

$$
z_{\text {fitting }}(x, y)=p_{00}+p_{10} x+p_{01} y+p_{20} x^{2}+p_{11} x y+p_{30} x^{3}+p_{21} x^{2} y
$$

where $p_{00}, p_{10}, p_{01}, p_{20}, p_{11}, p_{30}$ and $p_{21}$ are the polynomial fitting coefficients.

The fitted 3D FLS is shown in Fig. 2. The polynomial fitting coefficients of the 3D FLS are listed in Table 1. $R$-square $=0.998$ and $R M S E=0.002564$ indicate that the fitting result has a good accuracy. Thus, the 3D FLS could be used to determine the forming limit of any specific thickness in the TRB.

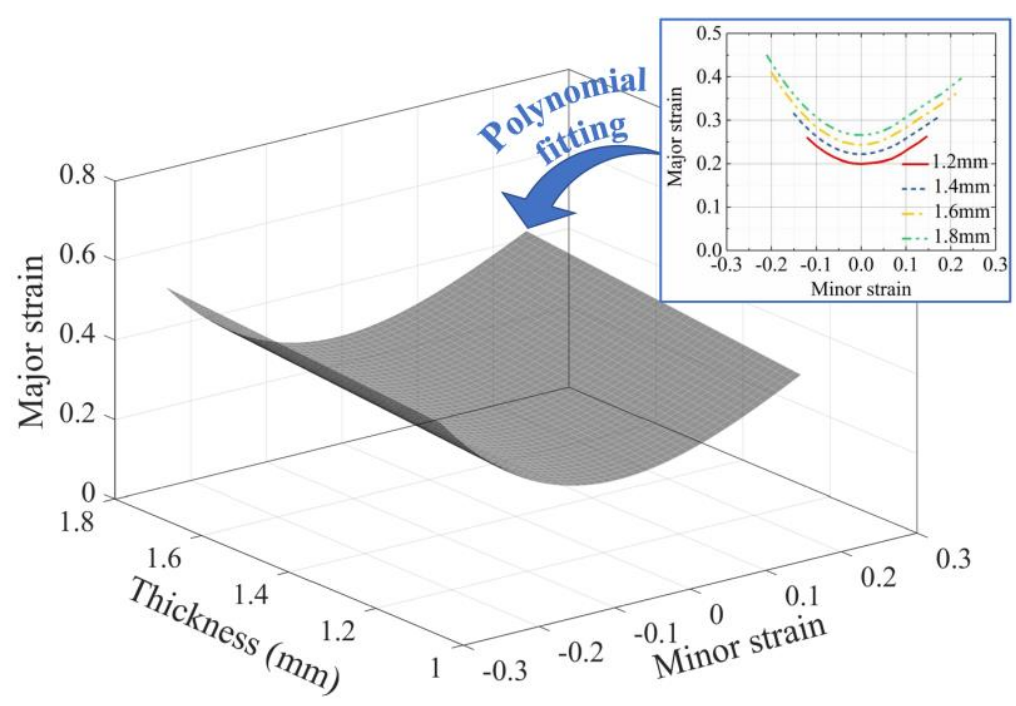

Fig. 2 3D FLS obtained by polynomial fitting 
Table 1 Polynomial fitting coefficients of the 3D FLS

\begin{tabular}{cccc}
\hline Coefficient & Value & Coefficient & Value \\
\hline$p_{00}$ & 0.05833 & $p_{21}$ & -0.3296 \\
$p_{10}$ & -0.08886 & $p_{30}$ & -4.458 \\
$p_{01}$ & 0.1174 & R-square & 0.998 \\
$p_{20}$ & 4.009 & RMSE & 0.002564 \\
$p_{11}$ & 0.07294 & & \\
\hline
\end{tabular}

\subsection{Forming margin field graph}

Cracking of the formed part could be judged qualitatively by the traditional FLD, while the safety degree of the non-cracking area and the cracking degree of the crack area could not be evaluated quantitatively. In previous studies, Naceur et al. [18] defined a constant as the "safety margin", which could be expressed as the difference between the major strain of the formed element and the corresponding major strain on the "secure FLC". Wei et al. [19] proposed an efficient method for controlling the forming quality, in which the distance between the strain state point and the FLC was regard as one of the constraints in the process of the blank metal forming optimization. In order to evaluate the formability of blank quantitatively, the forming margin was proposed in this paper. The forming margin refers to the formability of the blank after a certain degree of plastic deformation.

The minimum distance between the final strain state point of the element and the FLS at the same initial special thickness was defined as absolute value of the forming margin. In detail, the strain state and initial thickness could be represented as $P_{0}\left(x_{0}, y_{0}\right.$, $\left.z_{0}\right)$ in the coordinate space. The strain state and initial thickness on the FLS could be represented as $P(x, y, z)$, where, $\mathrm{x}, \mathrm{y}$ and $\mathrm{z}$ represent the minor strain, the thickness and the major strain respectively.

The thickness $y_{0}$ was brought into the fitting equation of the FLS to obtain the FLC corresponding to the thickness $y_{0}$. Then the FLS could be simplified as:

$$
z_{\text {fitting }}\left(x, y_{0}\right)=z
$$


$P\left(x, y_{0}, z\right)$ was a point on the FLC. The distance between the point $P_{0}$ and the point $P$ was the minimum distance between the point $P_{0}$ and the FLC. The point $P_{0}\left(x_{0}, y_{0}, z_{0}\right)$ and the point $P\left(x, y_{0}, z\right)$ satisfied the following conditions with on the $x-z$ plane:

$$
k_{p} \cdot k_{p p_{0}}=-1
$$

where $k_{p}$ is the tangent slope of the FLC at the point $P ; k_{P P O}$ is the slope of the line $P P_{0}$. Eq. (6) can be equivalent to the following equation:

$$
\frac{d\left(z_{\text {fitting }}\left(x, y_{0}\right)\right)}{d x}\left(z_{0}-z\right)=x-x_{0}
$$

By combining Eqs. (5) and (7), the point $P\left(x, y_{0}, z\right)$ could be obtained. Then the shortest distance between the point $P_{0}$ and the FLC could be calculated by the following Eq. (8), which was expressed as $d$.

$$
d=\sqrt{\left(z_{0}-z\right)^{2}+\left(x_{0}-x\right)^{2}}
$$

The forming margin could be expressed as:

$$
M= \begin{cases}d & z_{\text {fititing }}\left(x_{0}, y_{0}\right)-z_{0}>0 \\ 0 & z_{\text {fitting }}\left(x_{0}, y_{0}\right)-z_{0}=0 \\ -d & z_{\text {fitting }}\left(x_{0}, y_{0}\right)-z_{0}<0\end{cases}
$$

$z_{\text {fitting }}\left(x_{0}, y_{0}\right)-z_{0}>0$ indicates that the strain state point is below the FLS. As shown in Fig. $3, P_{01}$ is below the FLS, $P_{1}$ is on the FLS. The distance of line $P_{1} P_{01}$ is the minimum distance between $P_{01}$ and the FLC corresponding to the thickness $y_{01}$. The distance of line $P_{1} P_{01}$ is defined as the forming margin at the thickness $y_{01}$. As the $d$ decreases, the forming margin decreases and the formability of the blank decreases.

$z_{\text {fitting }}\left(x_{0}, y_{0}\right)-z_{0}<0$ indicates that the strain state point is above the FLS. As shown in Fig. $3, P_{02}$ is above the FLS; $P_{2}$ is on the FLS. The distance of line $P_{2} P_{02}$ is the minimum distance between $P_{02}$ and the FLC corresponding to the thickness $y_{02}$. The opposite value of the distance is defined as the forming margin at thickness $y_{02}$, which represents that cracking occurs during the forming process at this position. As the $d$ increases, the $-d$ decreases, which represents the forming margin decreases and the cracking degree of the blank increases.

$z_{\text {fitting }}\left(x_{0}, y_{0}\right)-z_{0}=0$ indicates that the strain state point is on the FLS, the blank is 
in a critical state of cracking.

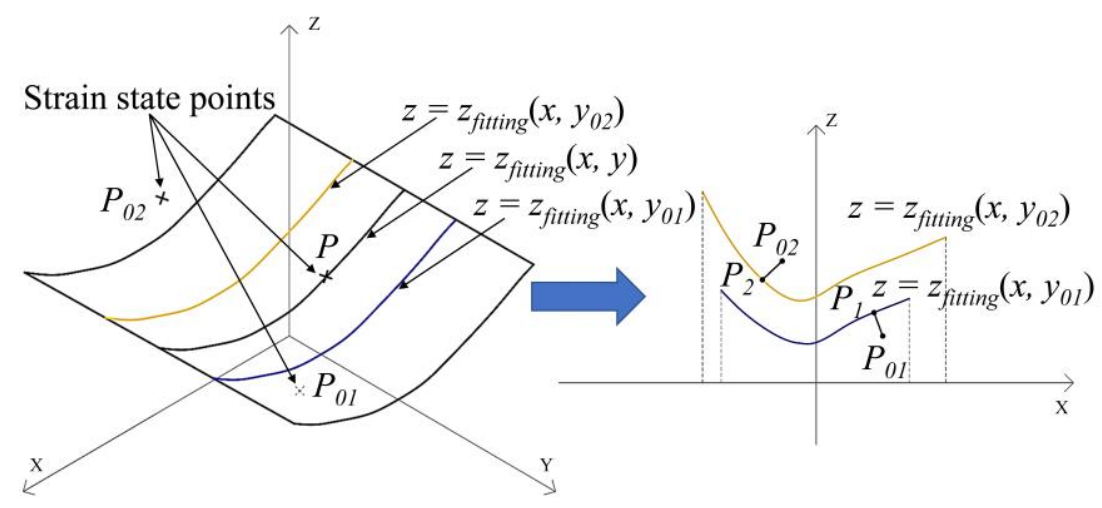

Fig. 3 3D FLD and definition of forming margin

The forming margin values of all elements in the simulation model were calculated. Then the color gradient was used to characterize the difference in forming margin of each element on the part. The forming margin filed graph was generated. The calculation process for all elements on the part is shown in Fig. 4.

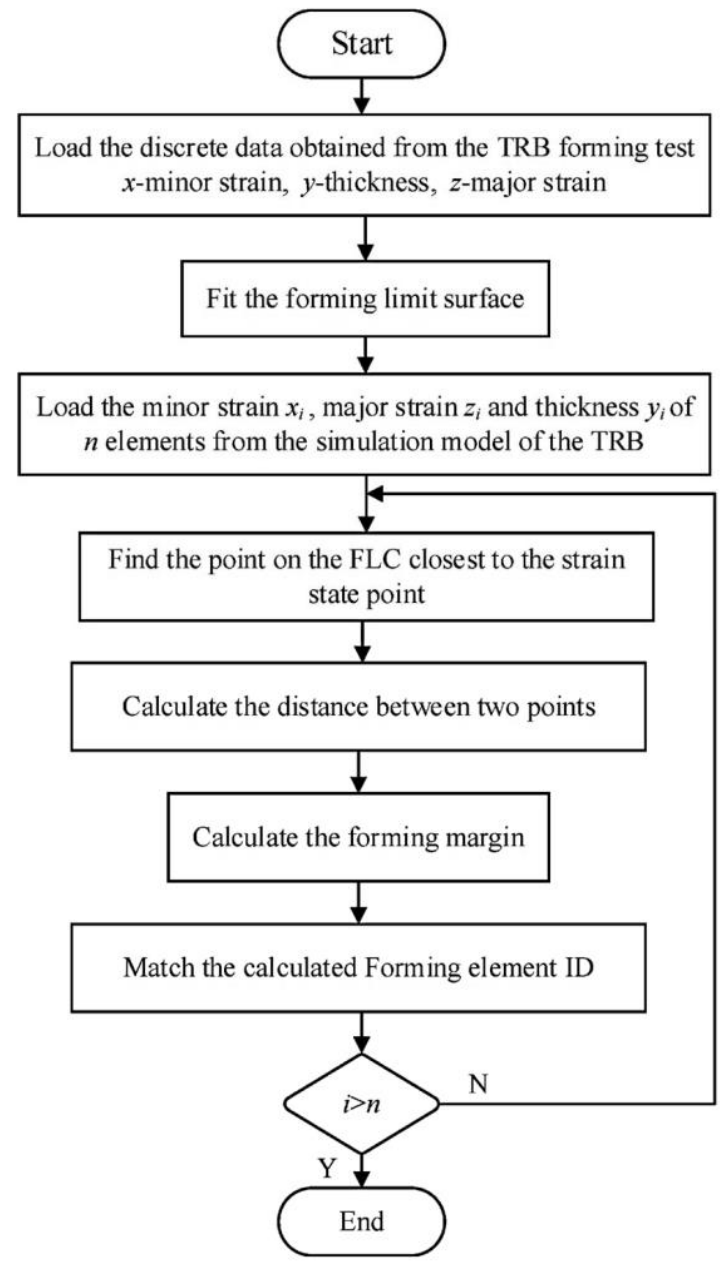

Fig. 4 Flow chart of forming margin calculation for all elements 
In the forming margin field graph, the different margins of elements on the part were expressed in different colors. The same color gradient was applied to the strain state points of the corresponding elements in the 3D FLD. The 3D FLD was used together with the forming margin field graph for TRB forming. The combination of two was called the forming limit margin field graph. By the forming limit margin field graph, the formability of the TRB could be quantified and the cracking in the forming process could be predicted.

\section{Simulation modeling and experiment}

\subsection{Materials}

The investigated TRB was made of the HC340LA cold rolled steel. Some mechanical properties [17] were listed in Table 2. The thickness of the investigated TRB was $1.2 / 1.6 \mathrm{~mm}$.

Table 2 Some mechanical properties of tested TRB

\begin{tabular}{ccc}
\hline Young's modulus $(\mathrm{GPa})$ & Poisson's ratio & Density $\left(\mathrm{kg} / \mathrm{m}^{3}\right)$ \\
\hline 210 & 0.3 & 7800 \\
\hline
\end{tabular}

As a simple and practical mechanical properties test method, uniaxial tensile test has been widely used. However, different strain hardening of the TRB could lead to different mechanical properties during the rolling process. Different mechanical properties should be considered in the different zones [20]. One way to obtain the mechanical properties in the thickness transition zone was by using the interpolation method based on the uniaxial tensile data in the constant thickness zone [9, 21].

The mechanical properties in the constant thickness zone were obtained by uniaxial tensile tests [17]. The true stress-true strain curves in the constant thickness zone were shown in Fig. 5(a). It was seen that the mechanical properties of two thicknesses had difference. The flow stress of the blank with the thickness of $1.2 \mathrm{~mm}$ was higher than the flow stress of the blank with the thickness of $1.6 \mathrm{~mm}$. To obtain the mechanical properties in the thickness transition zone, the Lagrange polynomial interpolation method was adopted based upon the mechanical properties in the constant thickness zone. Lagrange interpolation polynomial can be expressed as [22]: 


$$
p_{n}(\mathrm{x})=\sum_{i=0}^{n} f\left(\mathrm{x}_{i}\right) l_{i}(\mathrm{x})
$$

where $l_{i}(x)$ is Lagrange primary function, it can be expressed by following equation:

$$
l_{i}(x)=\frac{\left(x-x_{0}\right)\left(x-x_{1}\right) \ldots\left(x-x_{i-1}\right)\left(x-x_{i+1}\right) \ldots\left(x-x_{n}\right)}{\left(x_{i}-x_{0}\right)\left(x_{i}-x_{1}\right) \ldots\left(x_{i}-x_{i-1}\right)\left(x_{i}-x_{i+1}\right) \ldots\left(x_{i}-x_{n}\right)}(i=0,1, \ldots, n)
$$

$l_{i}(x)$ is an n-degree polynomial and has the following rule:

$$
l_{i}(x)=\delta_{i j}=\left\{\begin{array}{ll}
1 & i=j \\
0 & i \neq j
\end{array} i, j=0,1, \ldots, n .\right.
$$

$l_{0}(x), l_{1}(x), \ldots, l_{n}(x)$ are the Lagrange primary functions of $x_{0}, x_{1}, \ldots, x_{n}$. They are linearly independent quantities.

The 1.2/1.6 mm thickness transition zone was divided into 10 parts. Based on uniaxial tensile testing data in the $1.2 \mathrm{~mm}$ zone and $1.6 \mathrm{~mm}$ zone, mechanical properties of $1.22 \mathrm{~mm}, 1.26 \mathrm{~mm}, 1.30 \mathrm{~mm}, 1.34 \mathrm{~mm}, 1.38 \mathrm{~mm}, 1.42 \mathrm{~mm}, 1.46 \mathrm{~mm}, 1.50 \mathrm{~mm}, 1.54$ $\mathrm{mm}$ and $1.58 \mathrm{~mm}$ were obtained using Lagrange polynomial interpolation method. The mechanical properties of these interpolation points were combined to characterize the mechanical properties in the thickness transition zone, as shown in Fig. 5(b). Thus, the constitutive relation of TRB was completed by means of the combination of uniaxial tensile tests and Lagrange polynomial interpolation method.
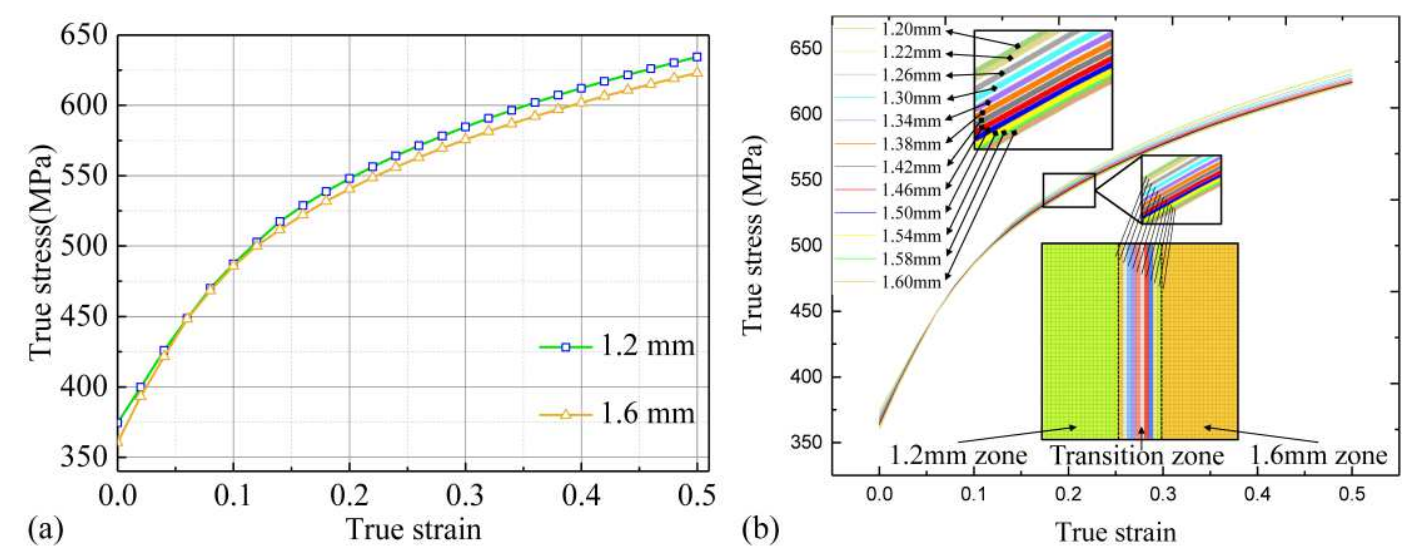

Fig. 5 True stress-true plastic strain curves of the TRB: (a) in the constant thickness zone; (b) in the thickness transition zone

\subsection{Numerical modeling}

The TRB bulging model was developed by using the HyperMesh, Dynaform and Matlab software. The schematic of TRB bulging modeling is shown in Fig. 6. The 
blank was modeled using four-node quadrilateral Belytschko-Tsay shell elements, which had 5 integration points in the thickness direction. In the model, the keyword *ELEMENT_SHELL_THICKNESS was used to change the thickness of the shell elements at the four nodes. As shown in Fig. 8, $\mathrm{T}_{1}-\mathrm{T}_{4}$ represented the thicknesses at nodes $\mathrm{N}_{1}-\mathrm{N}_{4}$, respectively. For elements in the constant thickness zone, the thicknesses were same at the four nodes $\left(T_{1}=T_{2}=T_{3}=T_{4}\right)$. For elements in the thickness transition zone, the interpolation method was employed to obtain the thicknesses according to the coordinate of the nodes $\left(\mathrm{T}_{1}=\mathrm{T}_{2}, \mathrm{~T}_{3}=\mathrm{T}_{4}\right)$. Each part was assigned the corresponding mechanical properties (see Fig. 5).

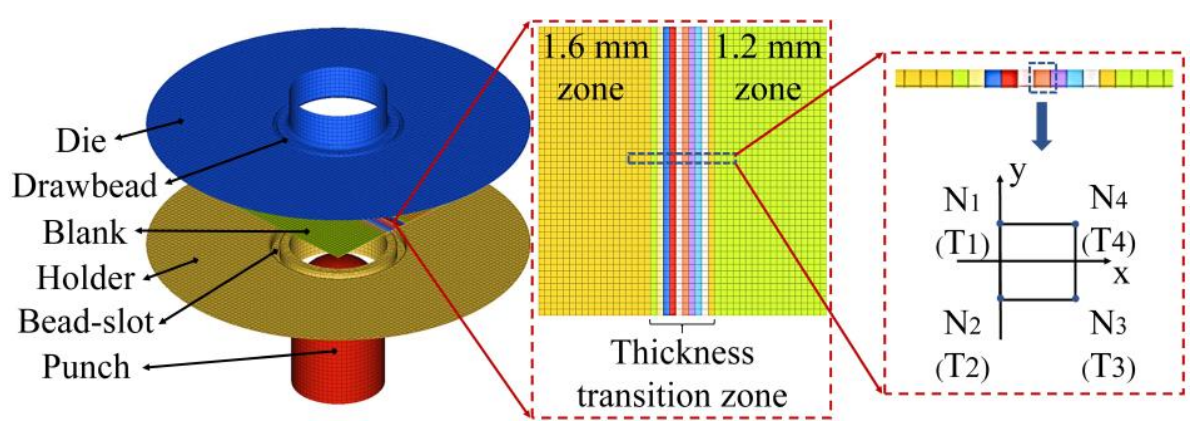

Fig. 6 Schematic of bulging modeling

In an ideal model, the thickness transition zone should be discretized into countless parts, the element size would be small. However, the small element size would result in high computational cost and numerical instability [21]. It was found that an element size of $4 \mathrm{~mm} \times 4 \mathrm{~mm}$ was sufficient in the thickness transition zone, while the thickness transition zone was discretized into 10 parts. Within the constant thickness zone, the $1.6 \mathrm{~mm}$ zone and the $1.2 \mathrm{~mm}$ zone were set to the other two parts, respectively. The average size of an element was $4 \mathrm{~mm} \times 3.89 \mathrm{~mm}$. The total number of the blank elements was 2070. The die, punch and holder were defined as rigid bodies, which were meshed automatically in Dynaform software. The total number of elements for the entire model was 19235. The major contact algorithm used was *CONTACT_FORMING_ONE_WAY_SURFACE_TO_SURFACE_ID. The virtual holder speed was set to $2000 \mathrm{~mm} / \mathrm{s}$, and the virtual stamping speed was set to 5000 $\mathrm{mm} / \mathrm{s}$. The strain distributions of the formed TRB specimens were obtained through model. The accurate strain distributions could lay the foundation for the application of 
the forming limit margin field graph.

\subsection{TRB bulging experiment}

The TRB bulging experiment was performed on the setup shown in Fig. 7. The TRB bulging experiments combined with the 3D DIC technology were carried out [23, 24]. The axisymmetric setup consisted of a pair of cameras, lights, a laser generator, a die, a holder and a hemispherical punch. The inner diameter of the die and the blank holder were both $105 \mathrm{~mm}$, the punch diameter was $100 \mathrm{~mm}$.

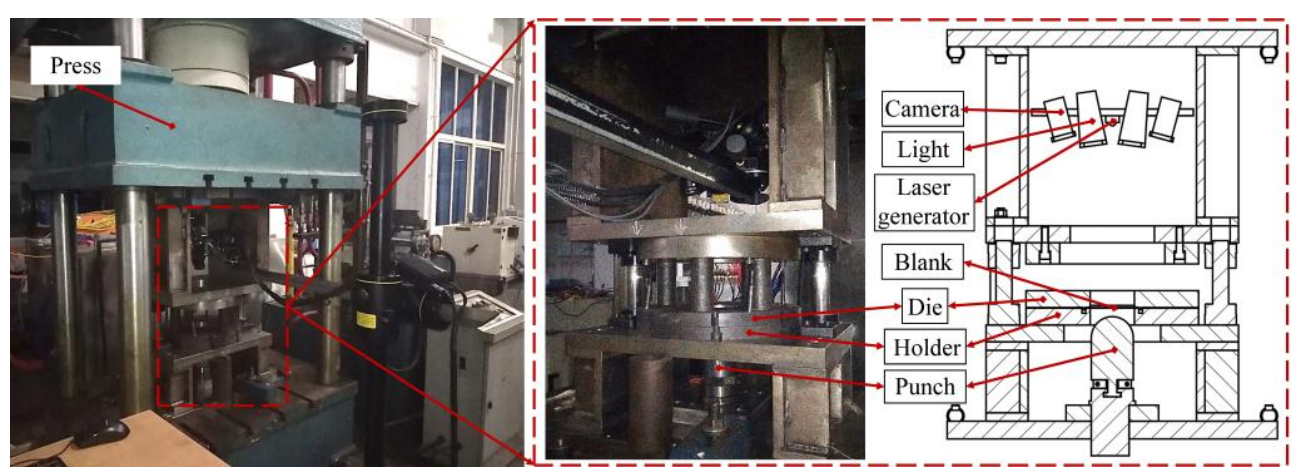

Fig. 7 TRB bulging experimental setup

The dimension of the TRB bulging specimen was $180 \mathrm{~mm} \times 180 \mathrm{~mm}$, as shown in the Fig. 8. The specimen had constant thickness zone and thickness transition zone. The constant thickness zone of TRB specimens contained the $1.2 \mathrm{~mm}$ zone and the 1.6 $\mathrm{mm}$ zone. The length of the $1.2 \mathrm{~mm}$ zone and $1.6 \mathrm{~mm}$ zone were both $70 \mathrm{~mm}$. The length of the thickness transition zone was $40 \mathrm{~mm}$. Taking the centerline of the specimen as the dividing line, the TRB bulging specimen was divided into thinner side and thicker side along the rolling direction.

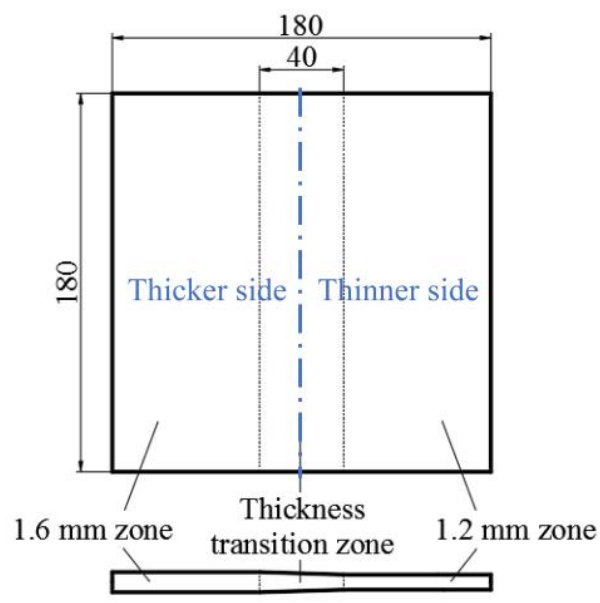

Fig. 8 Description of the TRB bulging specimen (Unit: mm) 
Prior to the experiments, the upper surfaces of the specimens were speckle patterned by spraying in the form of a random pattern of black colored spots on a white background. During the experiments, die moved downward to form the draw-bead on the specimens with the stationary blank holder. The whole deformation processes of the specimens were recorded by two cameras. The strain distributions of the specimens were calculated by the digital image processing algorithm. In order to ensure pictures could be recognized by the DIC system, the calibrated CCD cameras were placed in the appropriate position above the sample surface. The cameras were triggered before the specimens bulged. When the obvious necking or cracking occurred, the experiments were terminated.

\section{Results and Discussions}

\subsection{Simulation model verification}

The cracking position and shape of the formed specimens were used as two simple indexes to evaluate the accuracy of the model. The comparison between the simulation result and the experimental result is illustrated in Fig. 9. The cracking position of the TRB specimen was on the thinner side in the experiment in the simulation, the most severe thinning area was found on the thinner side. As shown in the Fig. 9, the red area (marked area in Fig. 9) was the most severely thinned area in the blank. In addition, the deformation shape of the formed specimen was basically the same in the experimental and simulation result. Therefore, it was initially indicated that the simulation model was accurate.
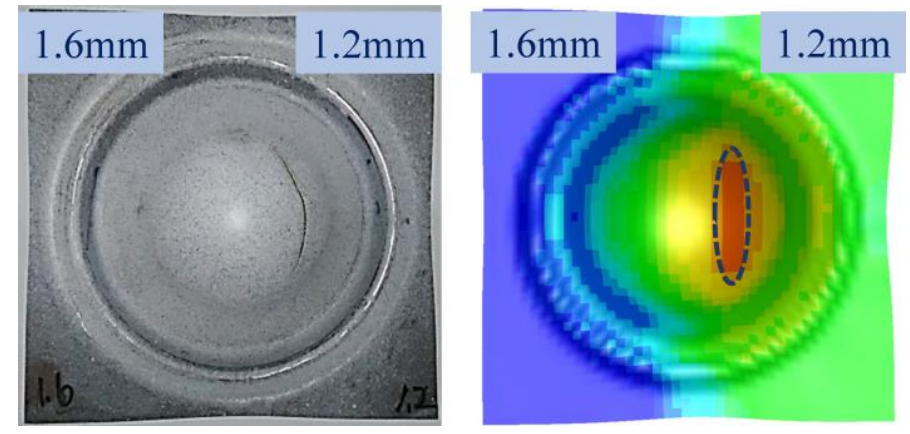

Fig. 9 Deformation comparison of experimental and simulation result

To prove the accuracy of the final strain distributions, the strain paths at three typical points were obtained by the simulation and the experiment, respectively. The 
first point was near the edge of cracking. The other two points and the first point were on a line. The distance between the points was $8 \mathrm{~mm}$. A comparison was made and the results are shown in Fig. 10. The strain paths at the $\mathrm{P}_{1}$ and $\mathrm{P}_{2}$ showed that the deviation between the major strains obtained by the simulation and those obtained through the experiment was large when the minor strain was small. Then with the increase of the minor strain, the deviation decreased gradually and coincided in a certain position. After that, with the increase of the minor strain, the deviation increased. At the final minor strain, the deviation between the final major strain obtained by the simulation and that obtained through the experiment reached $9.97 \%, 5.86 \%$, respectively. At the $\mathrm{P}_{3}$, the deviation between the major strain obtained by the simulation and that obtained through the experiment was $3.75 \%$ at the final minor strain. In the calculation of the forming limit margin, the final strains were used. Therefore, it was concluded that final strains obtained by simulation could be used.

(a)
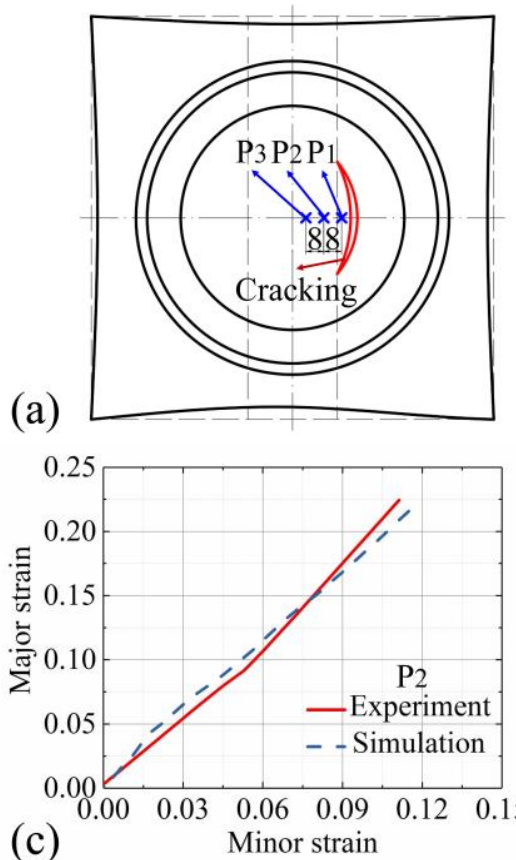

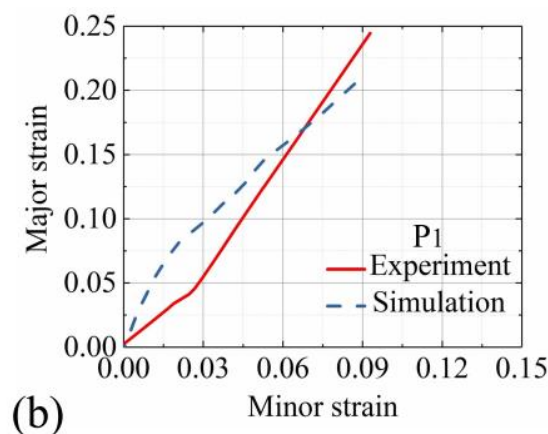

(b)

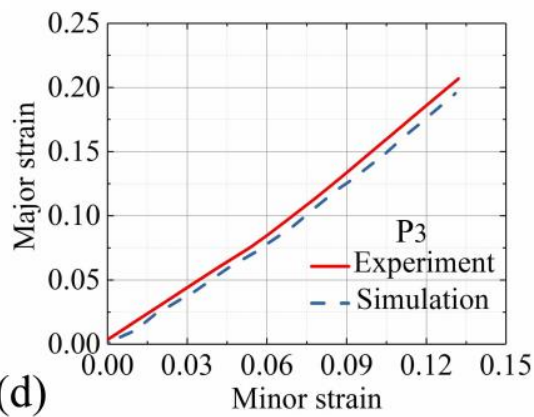

Fig. 10 Strain paths comparison of experimental and simulation result: (a) schematic diagram of cracking; (b) strain path at $\mathrm{P}_{1}$; (c) strain path at $\mathrm{P}_{2}$; (d) strain path at $\mathrm{P}_{3}$

In summary, the deformation of the specimens and the strain paths at the three typical points in simulation were proved by the experiment. Thus, the final major and minor strains could be used in the forming limit margin field graph to evaluate the formability of the TRB. 


\subsection{Quantitative evaluation of the formability before cracking}

Three forming limit margin field graphs under three different punch travels of 31.9 $\mathrm{mm}, 33.0 \mathrm{~mm}$ and $34.1 \mathrm{~mm}$ were established. As shown in Fig. 11, the 3D FLDs are on the left, and the forming margin field graphs are on the right.

In the 3D FLDs, as the punch travel increased, the strain state points were closer to the FLS. All strain state points were below the FLS. In the forming margin field graph, the forming margin distributions on the formed TRB part can be obtained intuitively. According to the cloud ruler, the minimum forming margin was 0.030 when the punch travel was $31.9 \mathrm{~mm}$. When the punch travel was $33.0 \mathrm{~mm}$, the minimum forming margin was 0.017 . When the punch travel reached $34.1 \mathrm{~mm}$, the minimum forming margin changed to 0.001 . The minimum forming margins were positive, which indicated that the formed TRB specimen was not cracked. As the punch travel increased, the minimum forming margin decreased, indicating that the formability of the TRB specimen decreased.
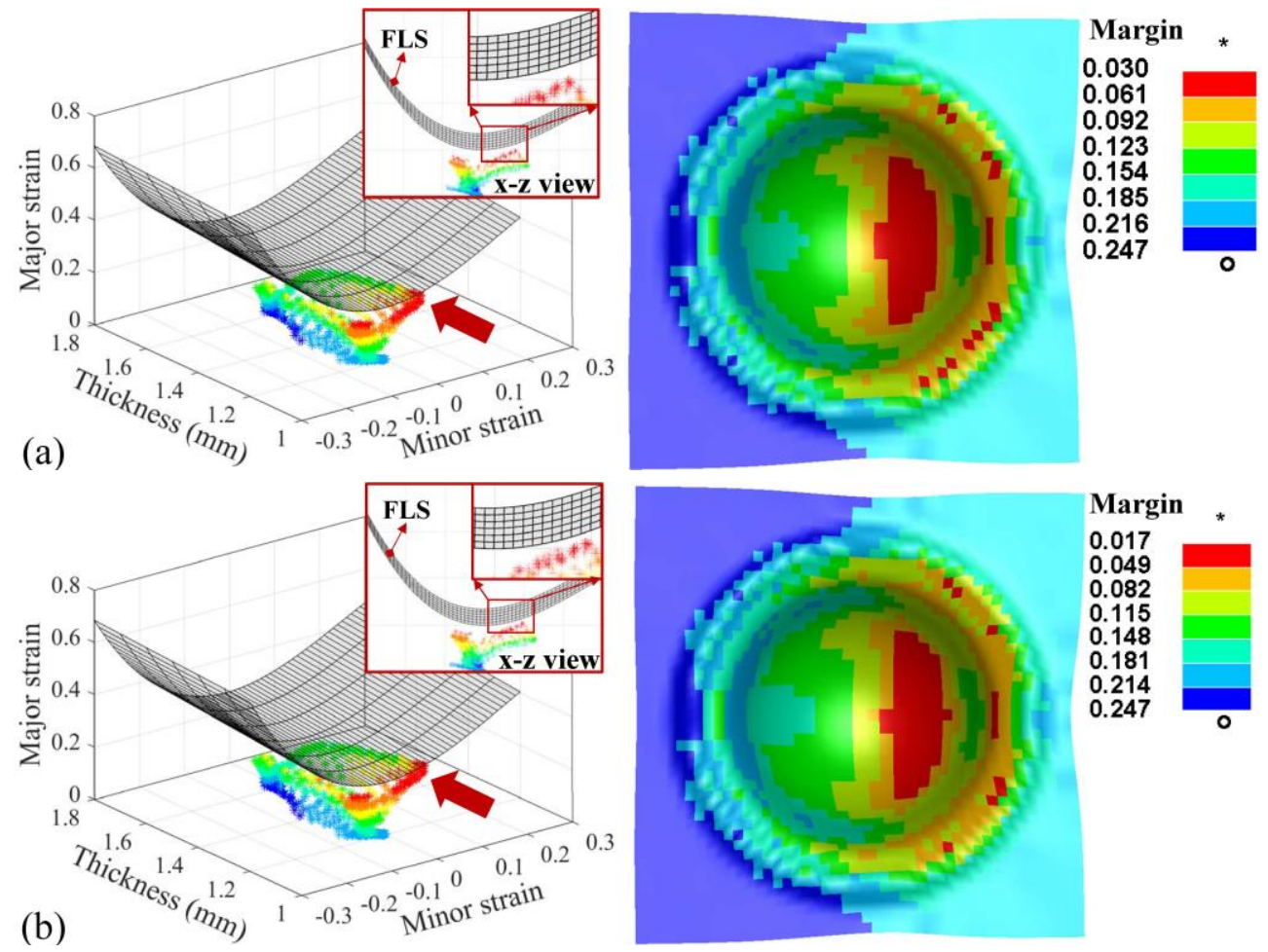

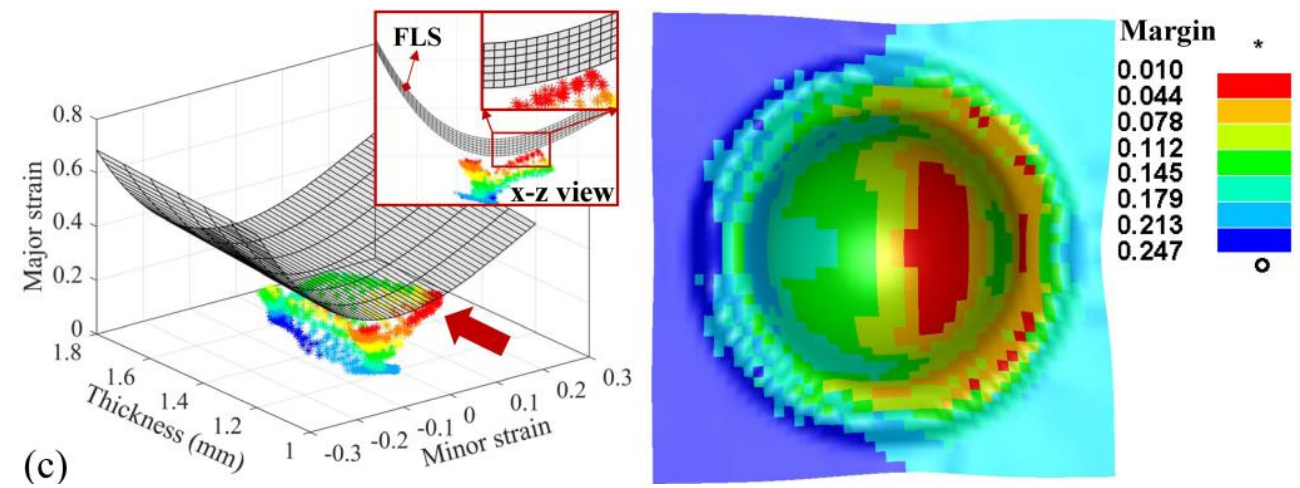

Fig. 11 Forming limit margin field graphs under three different punch travels: (a) punch travel of $31.9 \mathrm{~mm}$; (b) punch travel of $33.0 \mathrm{~mm}$; (c) punch travel of $34.1 \mathrm{~mm}$

\subsection{Cracking prediction and cracking degree evaluation}

As shown in Fig. 12, the other three forming limit margin field graphs under three different punch travels of $35.2 \mathrm{~mm}, 36.3 \mathrm{~mm}$ and $37.4 \mathrm{~mm}$ were established.

When the punch travel was $35.2 \mathrm{~mm}$ in the simulation, the forming limit margin field graph can be seen from Fig. 12(a). In the 3D FLD, all strain state points were below the FLS. Some of the strain state points near the FLS were displayed in red. The thickness coordinates of these red strain state points were within the range of $1.2 \mathrm{~mm}$ to $1.4 \mathrm{~mm}$. In the forming margin field graph, the forming margin distributions on the formed part can be obtained intuitively. According to the cloud ruler, the forming margins of the red area were between 0.002 and 0.037 , which indicated that the formed specimen was not cracked but the ability of material in the red area to continue to deform was insufficient. The red area was located on the thinner side.

When the punch travel reached $36.3 \mathrm{~mm}$ in the simulation, the forming limit margin field graph was shown in Fig. 12(b). In the 3D FLD, some strain state points marked red were located above the FLS. This indicated a cracking of the TRB specimen. The thickness coordinates of these strain state points were between $1.2 \mathrm{~mm}$ and $1.4 \mathrm{~mm}$. In the forming margin field graph, negative values appeared in the forming margins of all elements. The element with the minimum margin was on the thinner side. The minimum margin value was -0.012 , which meant that the formed specimen had cracked. Some elements near the draw bead were marked red (see in Fig. 12(b)), but their margin values were greater than zero, and there was no cracking.

When the punch continued to move, the travel reached $37.4 \mathrm{~mm}$ in the simulation. 
The forming limit margin field graph was obtained, as shown in Fig.12(c). In the 3D FLD, there were more strain state points marked red above the FLS. In the forming margin field graph. The minimum margin value was -0.024 . The absolute value of the minimum margin became greater than its value at the $36.3 \mathrm{~mm}$ punch travel. The TRB part cracked more seriously. The cracking position was on the thinner side. Similarly, the elements marked red near the draw bead did not crack.
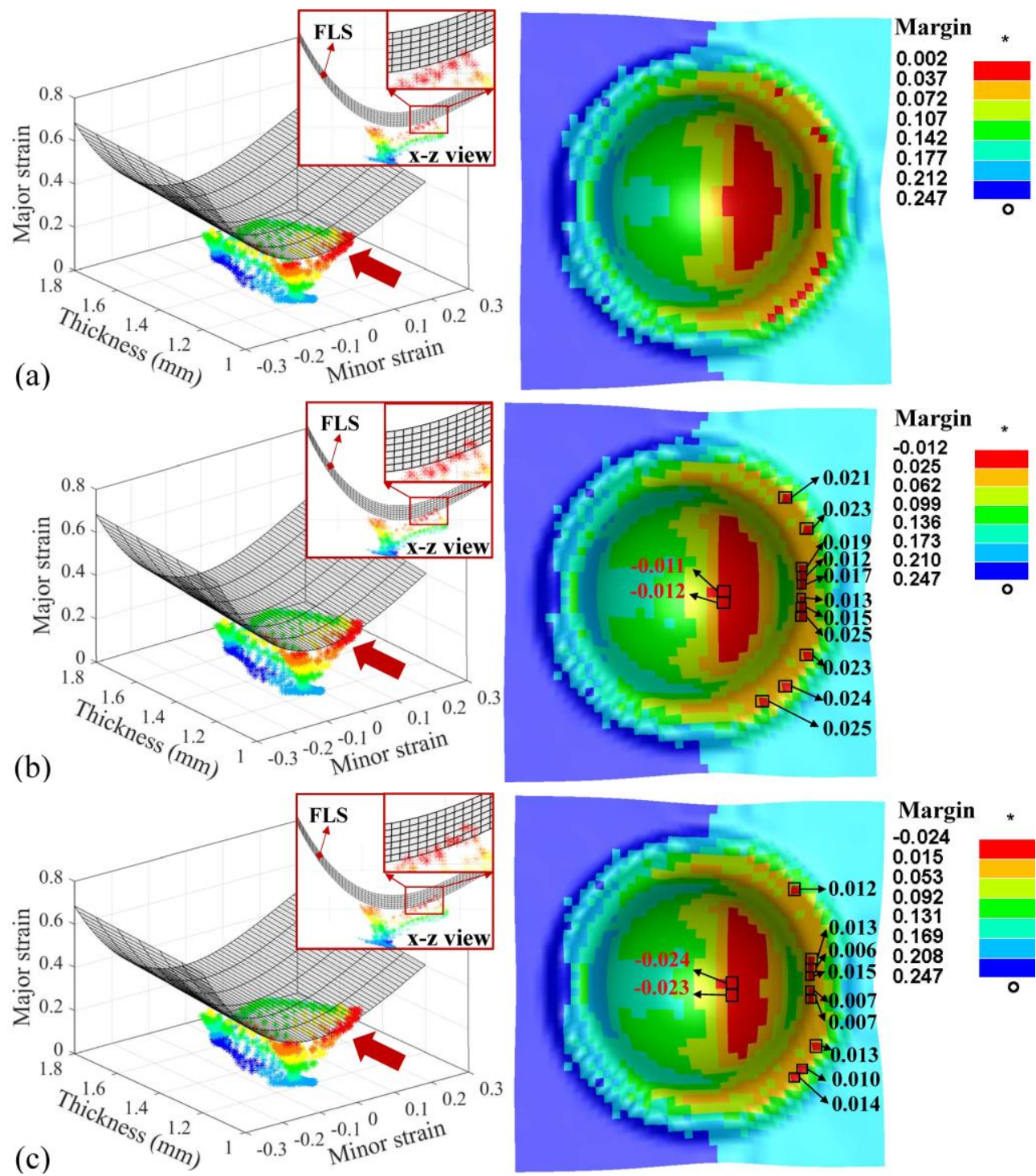

Fig. 12 Forming limit margin field graphs under three different punch travels: (a) punch travel of $35.2 \mathrm{~mm}$; (b) punch travel of $36.3 \mathrm{~mm}$; (c) punch travel of $37.4 \mathrm{~mm}$

At the three different punch travels, the minimum value of the forming margin, the maximum value of the forming margin and the number of cracking elements are shown in Table 3. As the punch travel increased, the minimum forming margin changed from 0.002 , to -0.012 , and to -0.024 . The minimum forming margin value changed from 
positive to negative, and the absolute value of the forming margin increased. The number of cracking elements was increased from 0 , to 8 , and to 26 . These results indicated that with the increase of the punch travel, the cracking degree increased.

Table 3 Forming margins and the number of cracking elements of three punch travels

\begin{tabular}{cccc}
\hline Travel (mm) & Min margin & Max margin & $\begin{array}{c}\text { Number of cracking } \\
\text { elements }\end{array}$ \\
\hline 35.2 & 0.002 & 0.247 & 0 \\
36.3 & -0.012 & 0.247 & 8 \\
37.4 & -0.024 & 0.247 & 26 \\
\hline
\end{tabular}

The result of the forming limit margin field graph was verified experimentally. In the experiments, the cracks occurred on the TRB parts when the punch travels were within the range of $33 \mathrm{~mm}$ to $35 \mathrm{~mm}$. The cracking positions were basically the same on the thinner side. With the further increase of the punch travel, the cracking enlarged further in the TRB bulging experiments. This phenomenon was consistent with the findings of Zhang et al. [25]. The forming limit on the thinner side was smaller than that on the thicker side. Under the same load, the stretching stress on the thinner side is greater than that on the thicker side. As a result, the thickness thinning of the thinner side was severe, and cracking eventually occurred.

\section{Conclusions}

In this paper, the influence of blank thickness on the TRB constitutive relation and formability was considered. A calculation method of the forming margin was proposed to quantify the formability. The forming limit margin field graph of TRB was established. The major conclusions could be drawn as follows:

(1) The deformation and strain paths predicted by simulation agreed well with that measured from experiments results, which indicated that the simulation model was reliable. The constitutive relation of the TRB established by means of the combination of the uniaxial tensile tests and the Lagrange polynomial interpolation method was credible.

(2) The forming margin was a quantification of the formability. During the TRB 
bulging process, the punch travel changed from $35.2 \mathrm{~mm}$, to $36.3 \mathrm{~mm}$, and to $37.4 \mathrm{~mm}$, the minimum forming margin value changed from 0.002 , to -0.012 , and to -0.024 . The TRB could continue to deform until TRB cracked, and eventually the cracking became more serious. The cracking occurred on the thinner side.

(3) The simulation and experiments proved the forming limit margin field graph was efficient. It was suitable for studying the formability of TRB and the prediction of cracking in the forming processes. The 3D FLS obtained based on the forming limit tests and polynomial fitting was reasonable.

\section{Acknowledgements}

This project is supported by National Natural Science Foundation of China (No. 51975202) and the Natural Science Foundation of Hunan Province (2019JJ30005).

\section{References}

1. Parente M, Safdarian R, Santos A D, Loureiro A, Vilaca P, Jorge R M N (2016) A study on the formability of aluminum tailor welded blanks produced by friction stir welding. Int J Adv Manuf Technol 83: 2129-2141. https://doi.org/10.1007/s00170-0157950-0

2. Jiang H, Zeng CC, Li GY, Cui JJ (2020) Effect of locking mode on mechanical properties and failure behavior of CFRP/Al electromagnetic riveted joint. Compos Struct 257:113162. https://doi.org/10.1016/j.compstruct.2020.113162

3. Cai D, Liang J, Ou H, Li GY, Cui JJ (2021) Mechanical properties and joining mechanism of electrohydraulic expansion joints for 6063 aluminum alloy/304 stainless steel thin-walled pipes. Thin-Walled Struct 161:107427. https://doi.org/10.1016/j.tws.2020.107427

4. Xu FX, Zhang X, Zhang H (2018) A review on functionally graded structures and materials for energy absorption. Eng Struct 171:309-325. https://doi.org/10.1016/j.engstruct.2018.05.094

5. Zhang SJ, Hu XL, Niu CL, Misra RDK, Yan S, Liu XH (2020) Annealing of HC340LA tailor rolled blanks-Control of mechanical properties and formability. J Mater Process Technol 281:116581. https://doi.org/10.1016/j.jmatprotec.2019.116581 6. Cheng W, Zhang HL, Fu S, Xie H, Tang ZW, Zhu ZL (2019) A process-performance 
coupled design method for hot-stamped tailor rolled blank structure. Thin-Walled Struct 140:132-143. https://doi.org/10.1016/j.tws.2019.03.037

7. Hirt G, Dávalos-Julca DH (2012) Tailored profiles made of tailor rolled strips by roll forming - part 1 of 2. Steel Res Int 83(1):100-105. https://doi.org/10.1002/srin.201100269

8. Meyer A, Wietbrock B, Hirt G (2008) Increasing of the drawing depth using tailor rolled blanks-Numerical and experimental analysis. Int J Mach Tools Manuf 48(5): 522-531. https://doi.org/10.1016/j.ijmachtools.2007.08.003

9. Zhang HW, Liu XH, Liu LZ, Hu P, Wu JL (2016) Forming limit and thickness transition zone movement for tailor rolled blank during drawing process. J Iron Steel Res Int 23(3):185-189. https://doi.org/10.1016/S1006-706X(16)30032-2

10. Chuang CH, Yang RJ, Li G, Mallela K, Pothuraju P (2008) Multidisciplinary design optimization on vehicle tailor rolled blank design. Struct. Multidiscip Optim 35(6):551560. https://doi.org/10.1007/s00158-007-0152-0

11. Bandyopadhyay K, Basak S, Panda SK, Saha P (2015) Use of stress based forming limit diagram to predict formability in two-stage forming of tailor welded blanks. Mater Des 67:558-570. https://doi.org/10.1016/j.matdes.2014.10.089

12. Goodwin GM (1968) Application of strain analysis to sheet metal forming problems in the press shop. Technical Paper No. 680093. Society of Automotive Engineers, New York

13. Ghazanfari A, Assempour A (2012) Calibration of forming limit diagrams using a modified Marciniak-Kuczynski model and an empirical law. Mater Des 34:185-191. https://doi.org/10.1016/j.matdes.2011.07.057

14. Abspoel M, Scholting ME, Droog JMM (2013) A new method for predicting forming limit curves from mechanical properties. J Mater Process Technol 213(5):759769. https://doi.org/10.1016/j.jmatprotec.2012.11.022

15. Kim S, Lee J, Barlat F, Lee MG (2013) Formability prediction of advanced high strength steels using constitutive models characterized by uniaxial and biaxial experiments. J Mater Process Technol 213(11):1929-1942. https://doi.org/10.1016/j.jmatprotec.2013.05.015 
16. Holmberg S, Enquist B, Thilderkvist P (2004) Evaluation of sheet metal formability by tensile tests. J Mater Process Technol 145(1):72-83. https://doi.org/10.1016/j.jmatprotec.2003.07.004

17. Ou H, Yang YH, Hu M, Li GY, Cui JJ (2019) Forming study on a tailor rolled blank (TRB) structure-Formability evaluation and model verification. J Manuf Process 44:397-407. https://doi.org/10.1016/j.jmapro.2019.06.004

18. Naceur H, Delaméziere A, Batoz JL, Guo YQ, Knopf-Lenoir C (2004) Some improvements on the optimum process design in deep drawing using the inverse

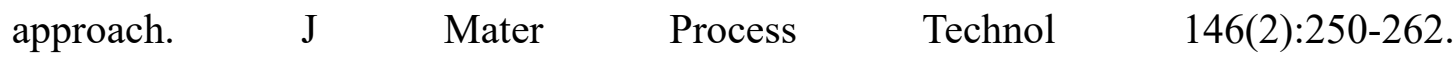
https://doi.org/10.1016/j.jmatprotec.2003.11.015

19. Wei DL, Cui ZS, Chen J (2008) Optimization and tolerance prediction of sheet metal forming process using response surface model. Comput Mater Sci 42(2):228-233. https://doi.org/10.1016/j.commatsci.2007.07.014

20. Merklein M, Johannes M, Lechner M, Kuppert A (2014) A review on tailored blanks-production, applications and evaluation. J Mater Process Technol 214(2):151164. https://doi.org/10.1016/j.jmatprotec.2013.08.015

21. Sun GY, Zhang HL, Lu GX, Guo JW, Cui JJ, Li Q (2017) An experimental and numerical study on quasi-static and dynamic crashing behaviors for tailor rolled blank $\begin{array}{lllll}\text { (TRB) } & \text { structures. } & \text { Mater } & \text { Des } & 118: 175-197 .\end{array}$ https://doi.org/10.1016/j.matdes.2016.12.073

22. Zhang HW, Liu XH, Liu LZ, Hu P, Wu JL (2015) Study on nonuniform deformation of tailor rolled blank during uniaxial tension. Acta Metall Sin-Engl 28(9):1198-1204. https://doi.org/10.1007/s40195-015-0313-x

23. Peters WH, Ranson WF (1982) Digital imaging techniques in experimental stress analysis. Opt Eng 21(3):213427. https://doi.org/10.1117/12.7972925

24. Yamaguchi I (1982) Simplified laser-speckle strain gauge. Opt Eng 21(3):213436. https://doi.org/10.1117/12.7972927

25. Zhang HW, Wu JL, Wang XG (2018) Crack defect of tailor rolled blank in deep drawing process. J Iron Steel Res Int 25:1237-1243. https://doi.org/10.1007/s42243018-0184-2 


\section{Figure captions}

Fig. 1 A schematic of TRB technology (adapted from Ref. [4])

Fig. 2 3D FLS obtained by polynomial fitting

Fig. 3 3D FLD and definition of forming margin

Fig. 4 Flow chart of forming margin calculation for all elements

Fig. 5 True stress-true plastic strain curves of the TRB: (a) in the constant thickness zone; (b) in the thickness transition zone

Fig. 6 Schematic of bulging modeling

Fig. 7 TRB bulging experimental setup

Fig. 8 Description of the TRB bulging specimen (Unit: $\mathrm{mm}$ )

Fig. 9 Deformation comparison of experimental and simulation result

Fig. 10 Strain paths comparison of experimental and simulation result: (a) schematic diagram of cracking; (b) strain path at P1; (c) strain path at P2; (d) strain path at P3 Fig. 11 Forming limit margin field graphs under three different punch travels: (a) punch travel of $31.9 \mathrm{~mm}$; (b) punch travel of $33.0 \mathrm{~mm}$; (c) punch travel of $34.1 \mathrm{~mm}$ Fig. 12 Forming limit margin field graphs under three different punch travels: (a) punch travel of $35.2 \mathrm{~mm}$; (b) punch travel of $36.3 \mathrm{~mm}$; (c) punch travel of $37.4 \mathrm{~mm}$ 


\section{Table captions}

Table 1 Polynomial fitting coefficients of the 3D FLS

Table 2 Some mechanical properties of tested TRB

Table 3 Forming margins and the number of cracking elements of three punch travels 


\section{Declarations}

\section{Funding}

This project is supported by National Natural Science Foundation of China (No. 51975202) and the Natural Science Foundation of Hunan Province (2019JJ30005).

\section{Conflicts of interest/Competing interests}

Conflict of Interest for all authors - None.

\section{Availability of data and material}

The raw/processed data and material required to reproduce these findings cannot be shared at this time due to technical or time limitations.

\section{Code availability}

Not applicable.

\section{Authors' contributions}

Da Cai: Writing - Original Draft, Methodology. Hang Ou: Data Curation. Ming Hu: Methodology, Software. Guangyao Li: Investigation. Junjia Cui: Writing Review \& Editing, Funding acquisition. 
Figures

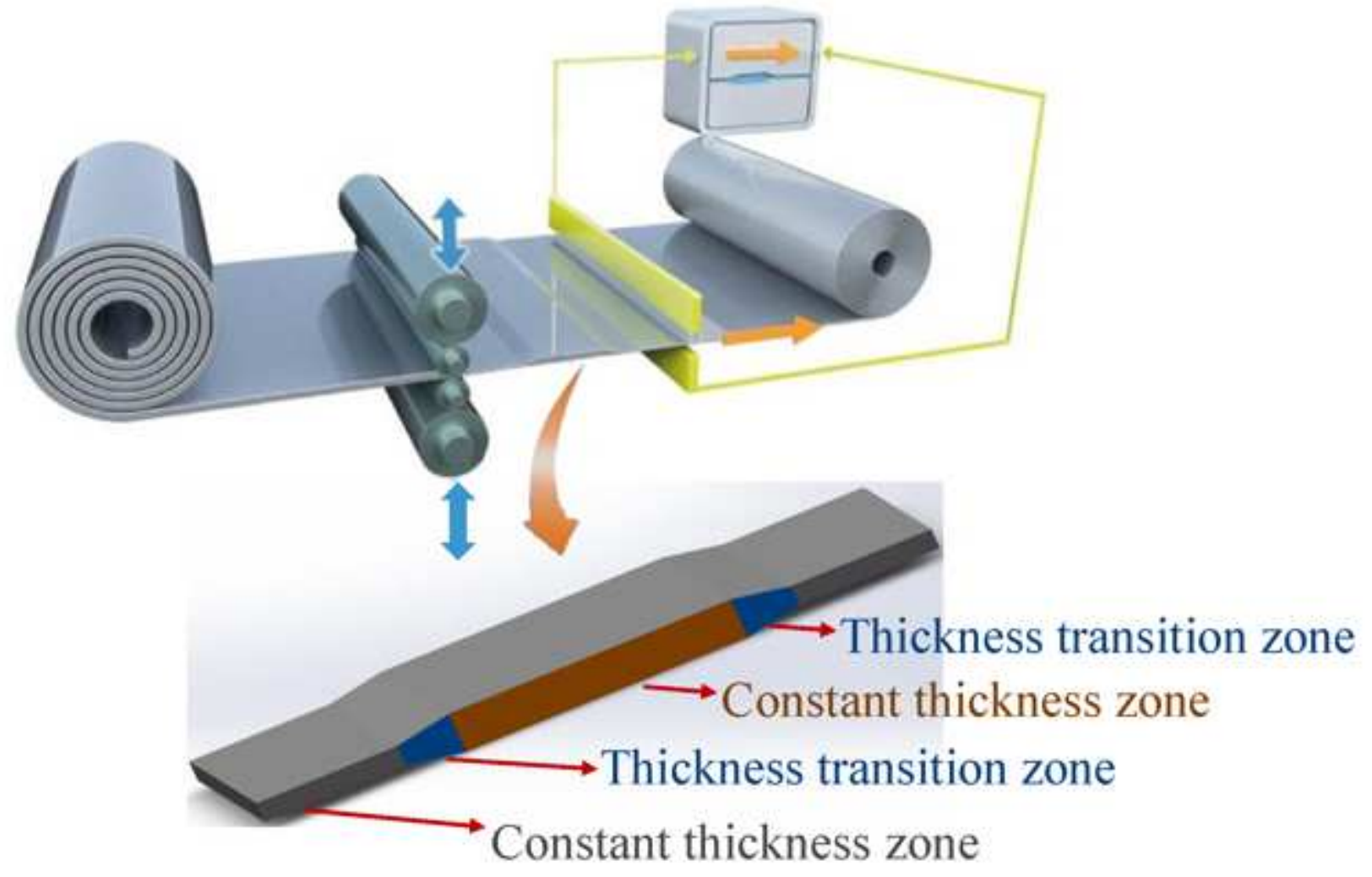

Figure 1

A schematic of TRB technology (adapted from Ref. [4]) 


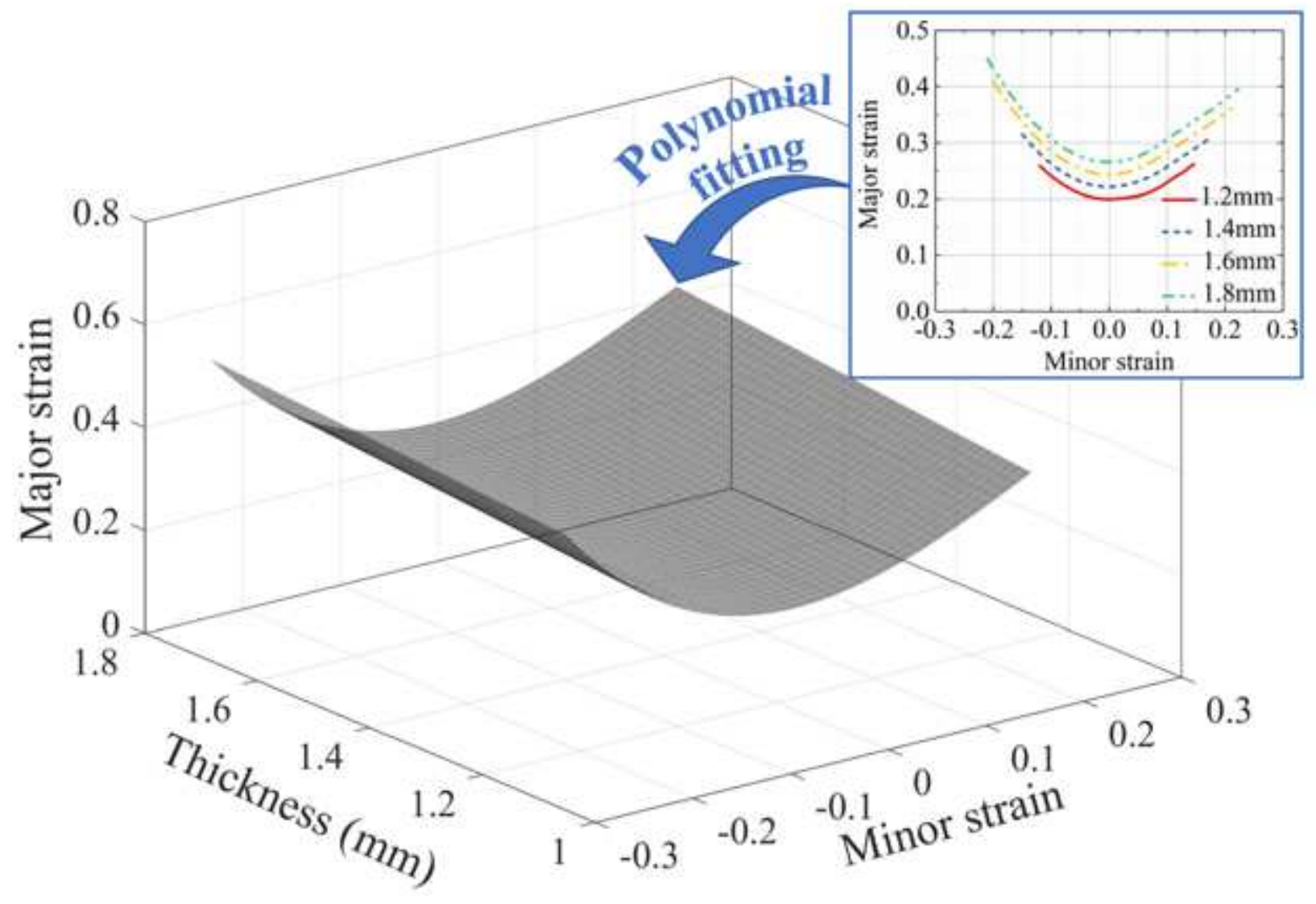

Figure 2

3D FLS obtained by polynomial fitting

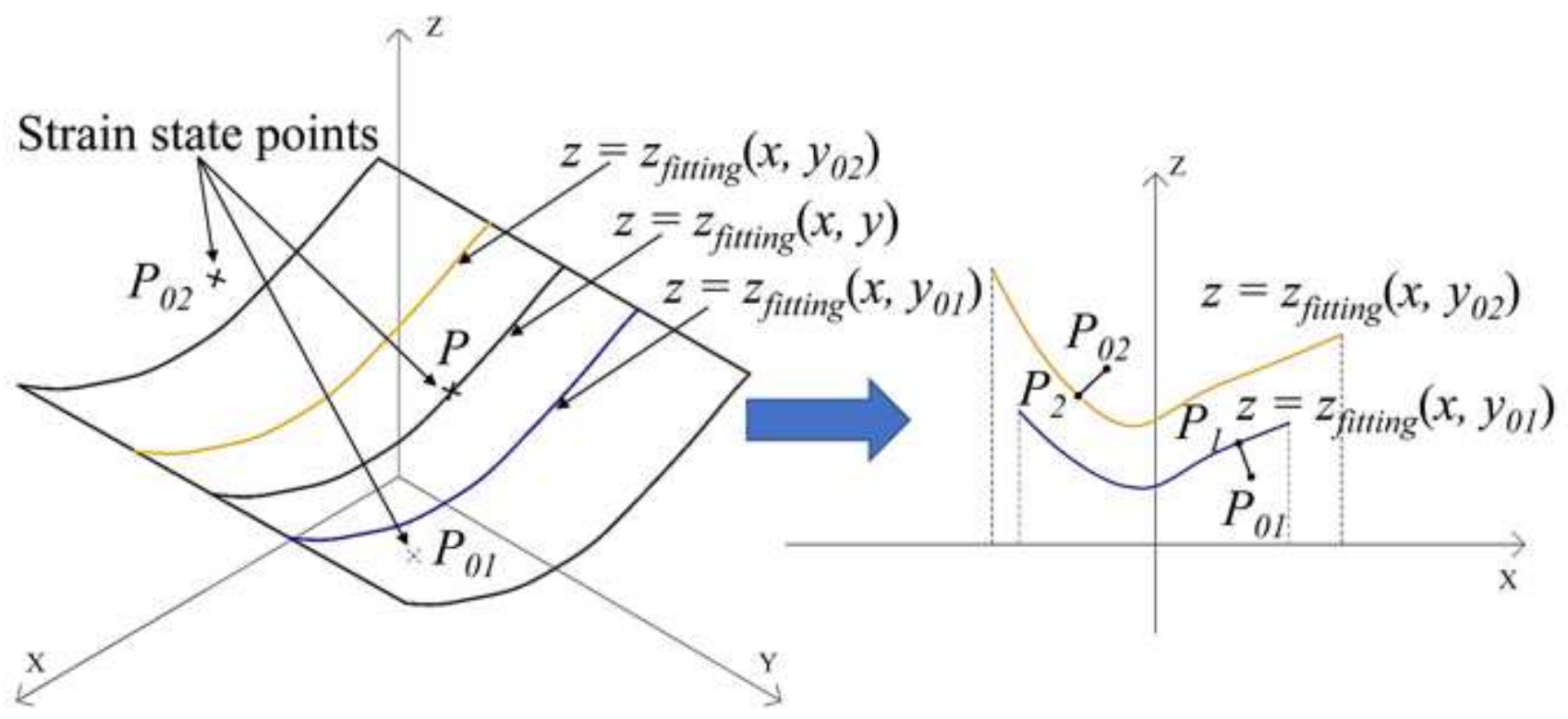

Figure 3 


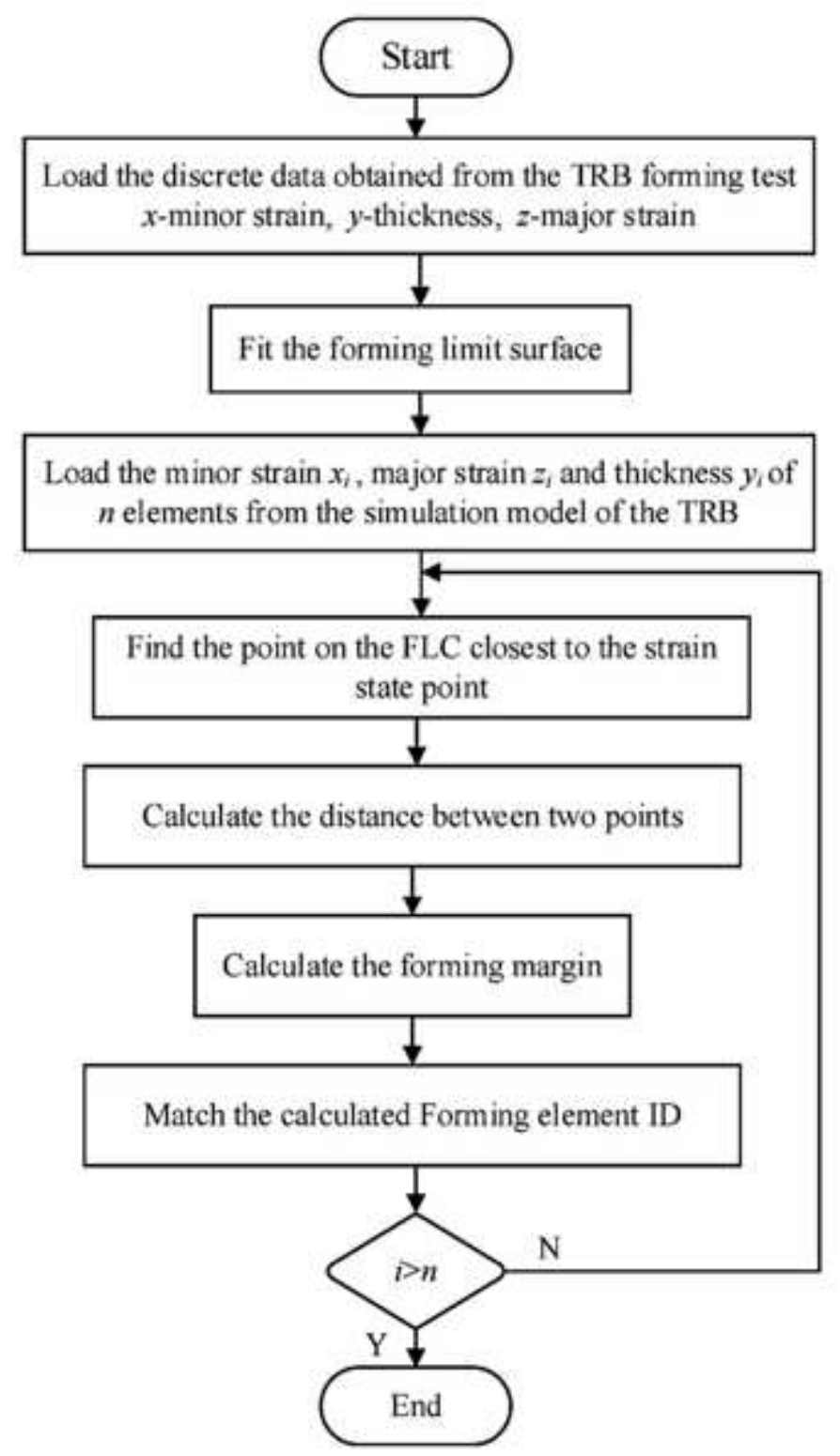

Figure 4

Flow chart of forming margin calculation for all elements 

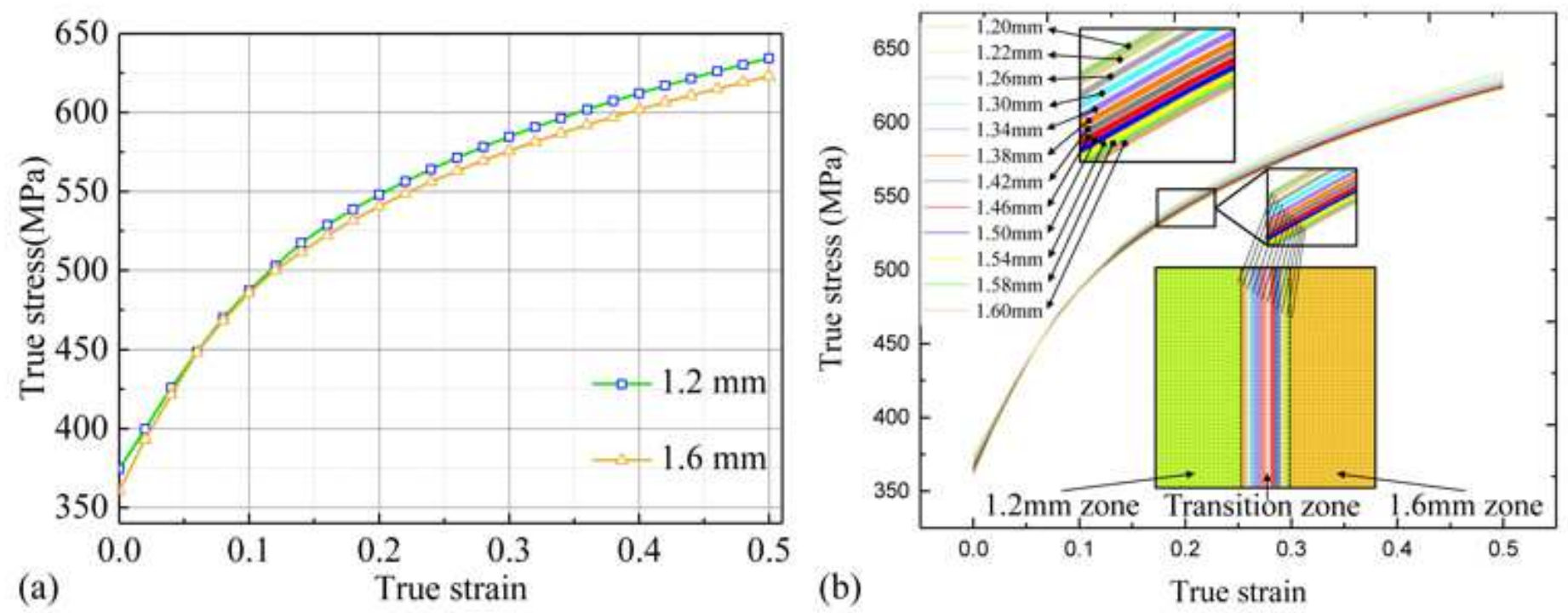

Figure 5

True stress-true plastic strain curves of the TRB: (a) in the constant thickness zone; (b) in the thickness transition zone

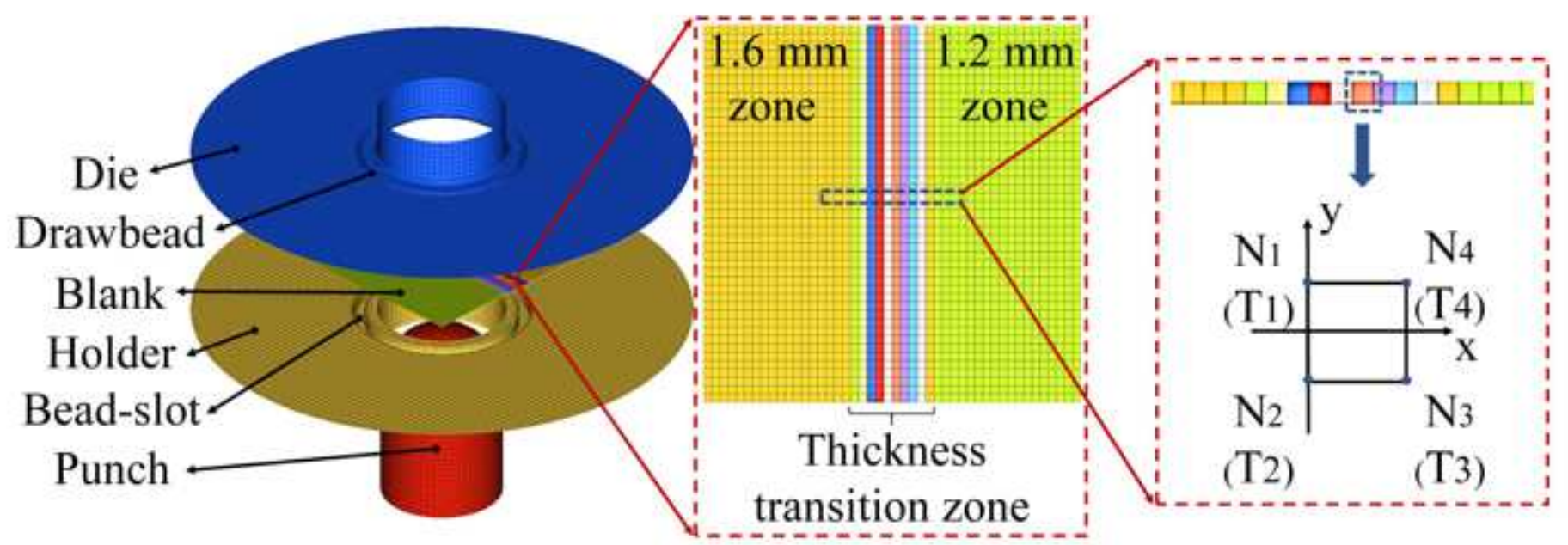

Figure 6

Schematic of bulging modeling 


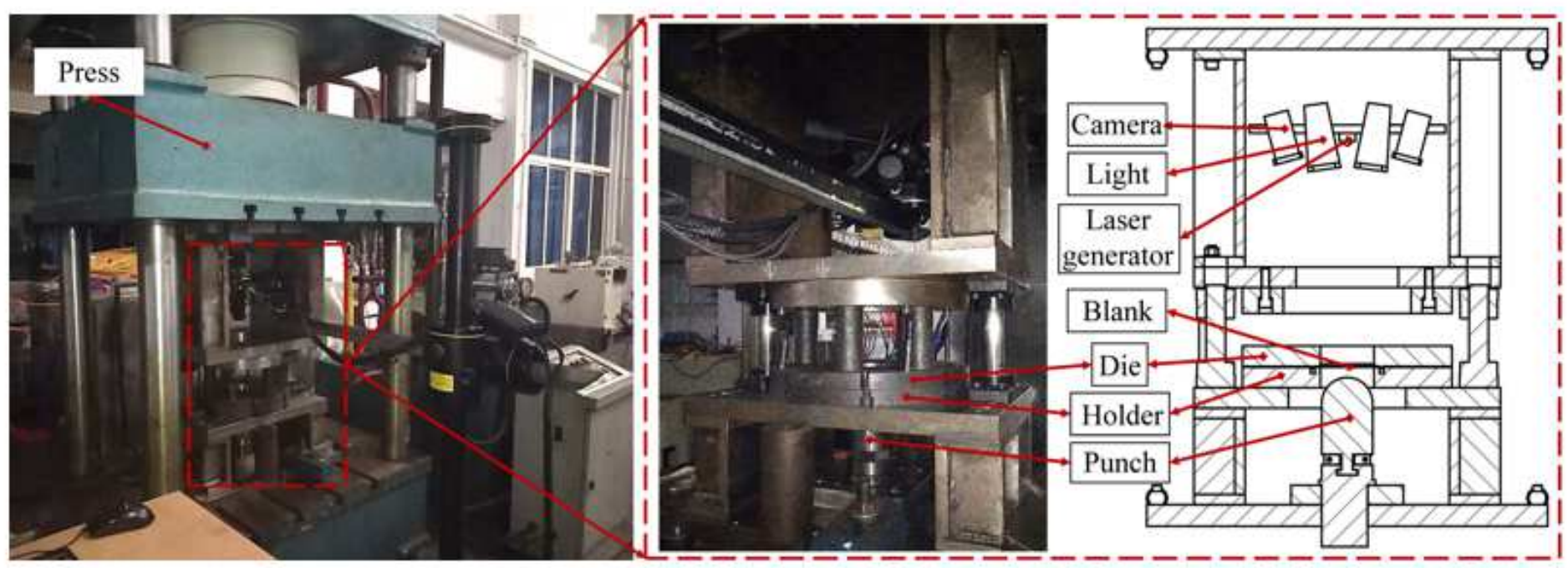

Figure 7

TRB bulging experimental setup

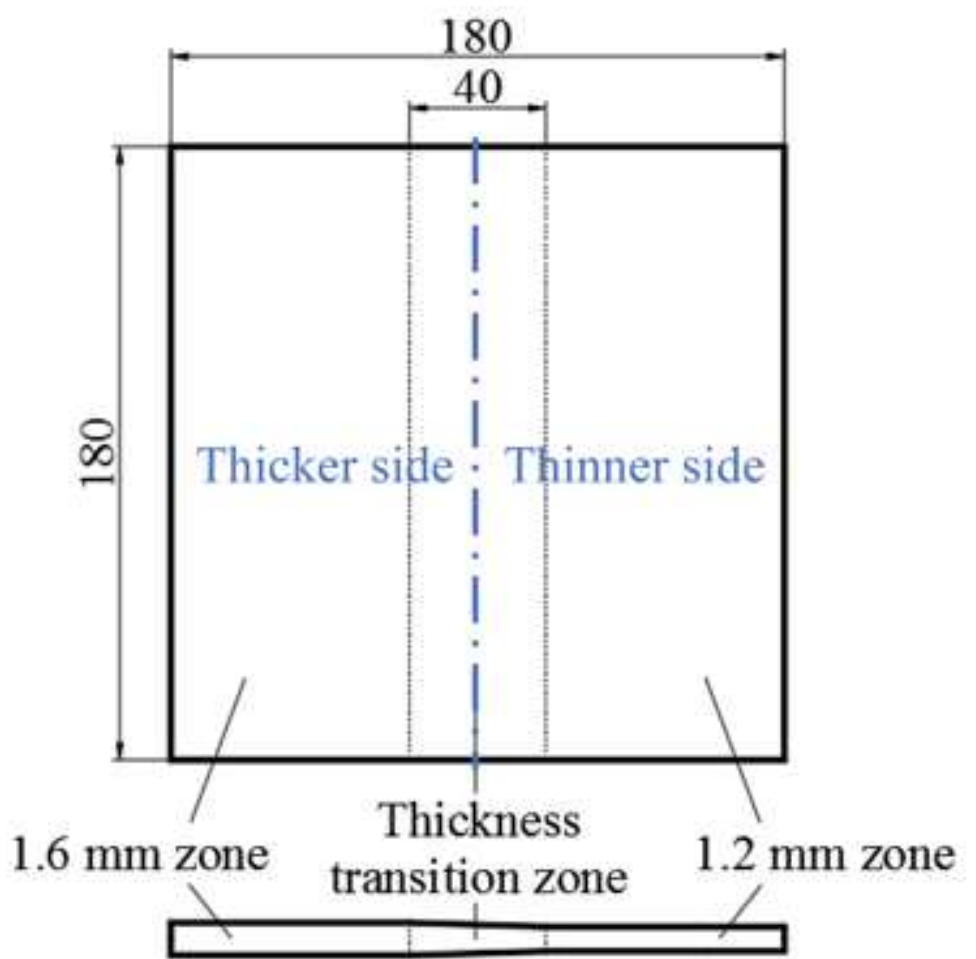

Figure 8

Description of the TRB bulging specimen (Unit: mm) 

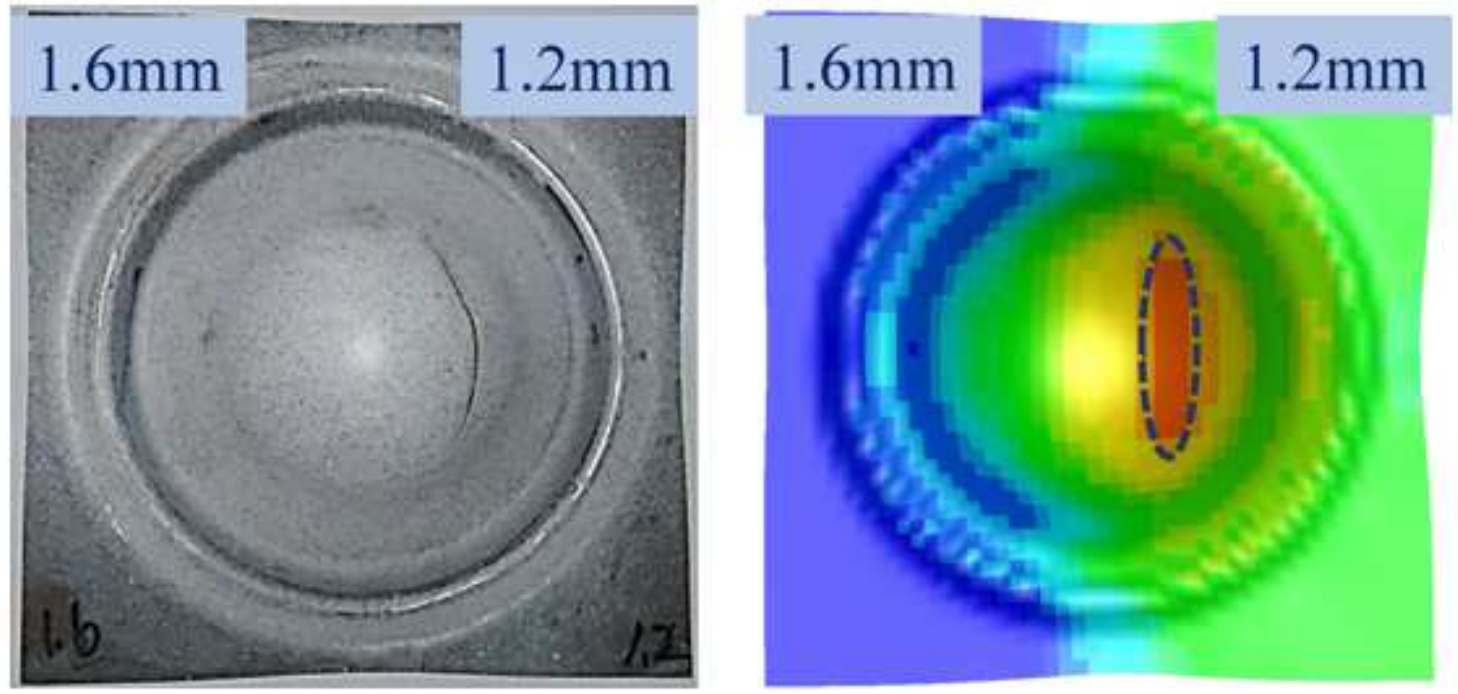

Figure 9

Deformation comparison of experimental and simulation result 

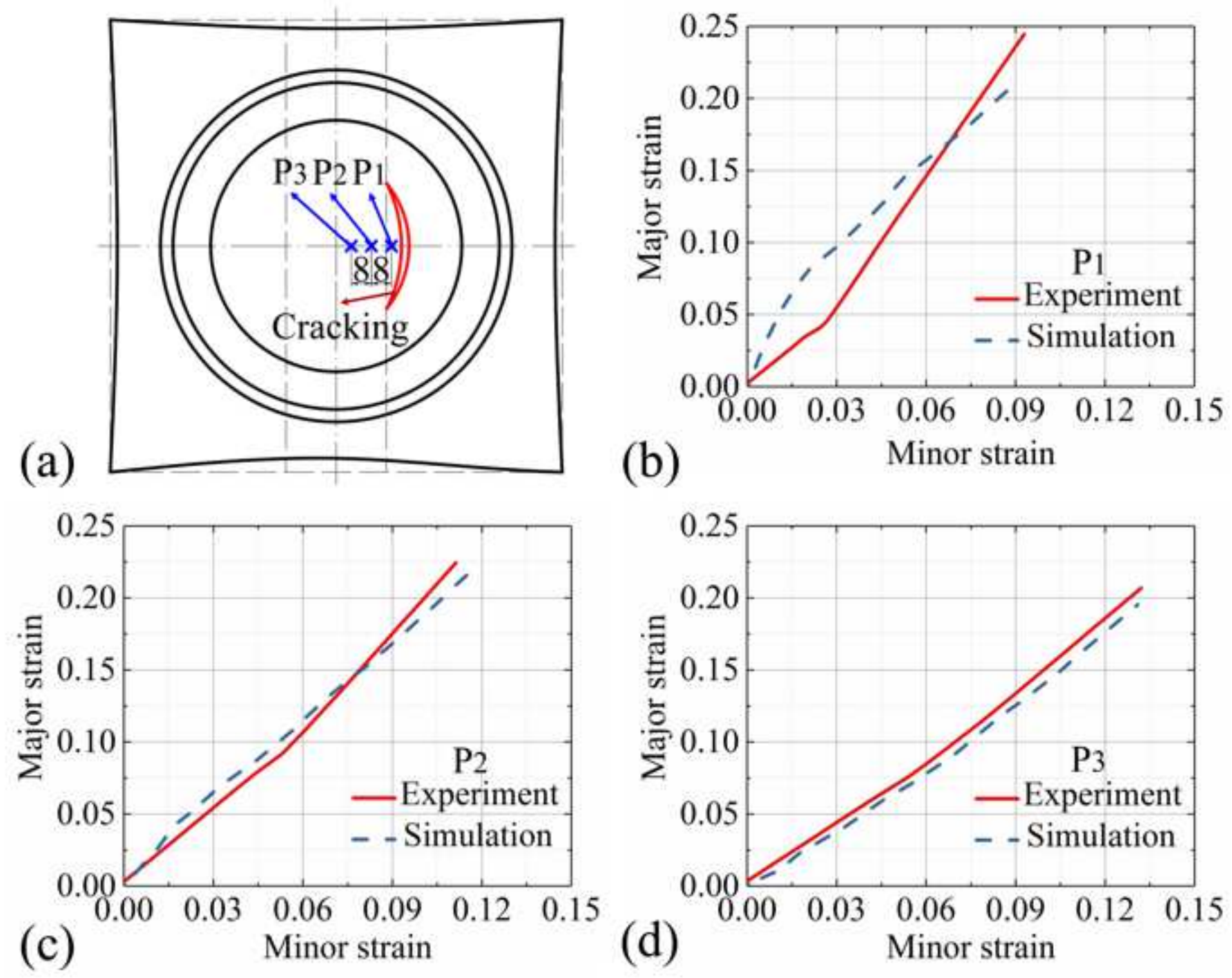

Figure 10

Strain paths comparison of experimental and simulation result: (a) schematic diagram of cracking; (b) strain path at P1; (c) strain path at P2; (d) strain path at P3 

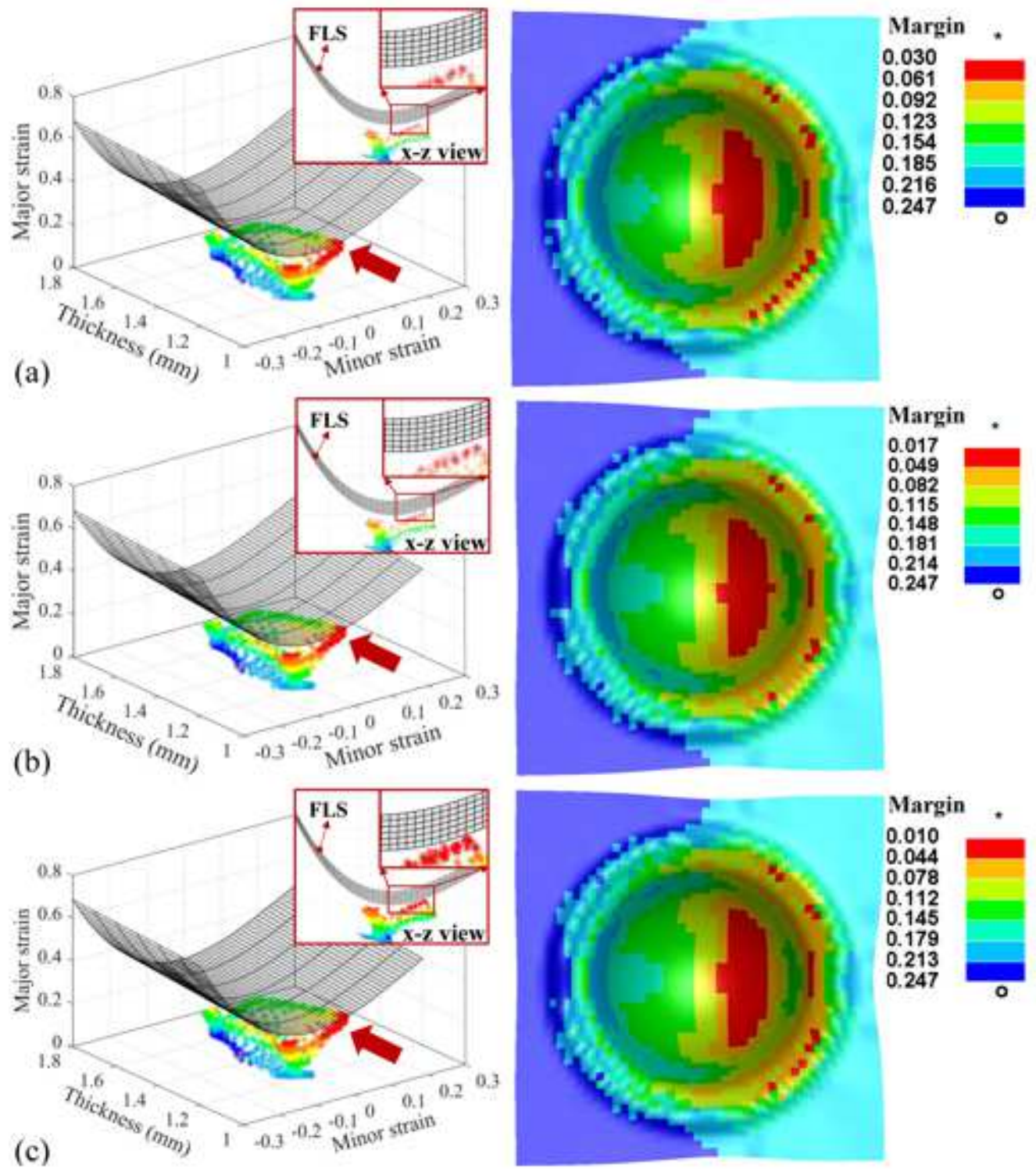

Figure 11

Forming limit margin field graphs under three different punch travels: (a) punch travel of $31.9 \mathrm{~mm}$; (b) punch travel of $33.0 \mathrm{~mm}$; (c) punch travel of $34.1 \mathrm{~mm}$ 

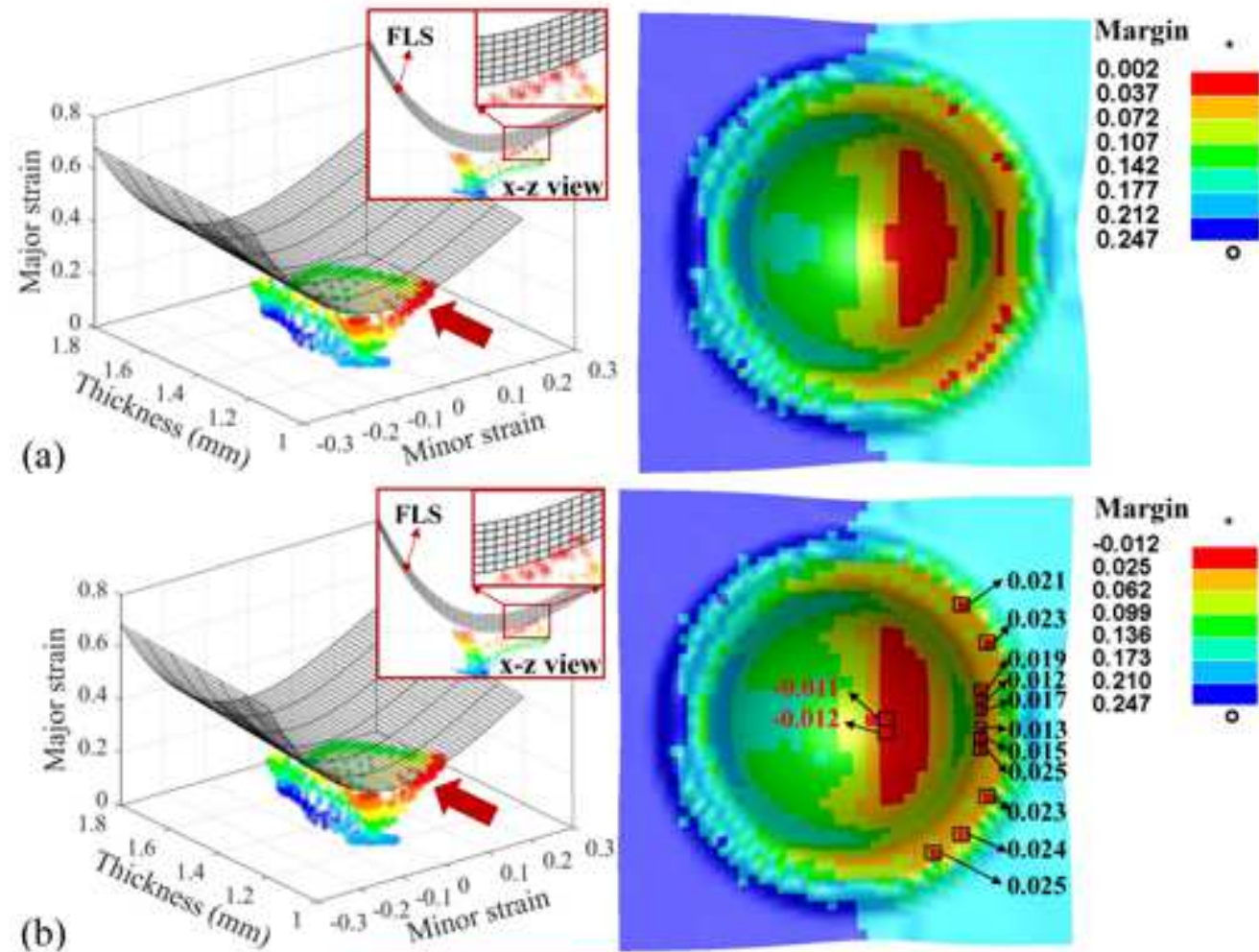

\section{Margin}

$-0.012$

0.025

0.062

0.099

0.173

$\begin{array}{ll}0.210 & \end{array}$
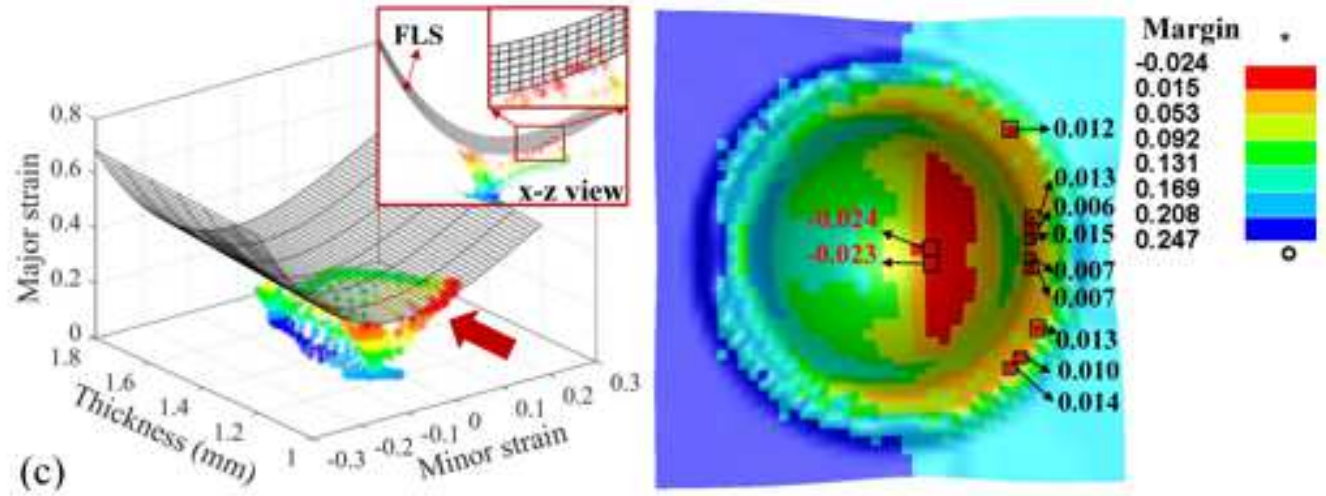

Figure 12

Forming limit margin field graphs under three different punch travels: (a) punch travel of $35.2 \mathrm{~mm}$; (b) punch travel of $36.3 \mathrm{~mm}$; (c) punch travel of $37.4 \mathrm{~mm}$ 